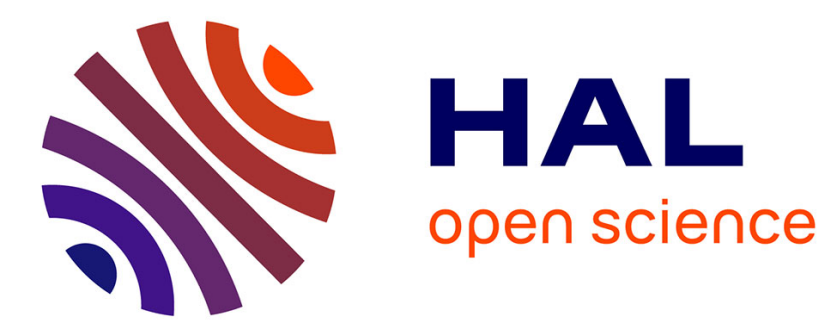

\title{
Effect of aging temperature on a thermoset-like novel acrylic thermoplastic composite for marine vessels
}

\author{
Haithem Bel Haj Frej, Romain Léger, Didier Perrin, Patrick Ienny
}

\section{To cite this version:}

Haithem Bel Haj Frej, Romain Léger, Didier Perrin, Patrick Ienny. Effect of aging temperature on a thermoset-like novel acrylic thermoplastic composite for marine vessels. Journal of Composite Materials, 2021, 55 (19), pp.002199832199678. 10.1177/0021998321996780 . hal-03154606

\author{
HAL Id: hal-03154606 \\ https://hal.science/hal-03154606
}

Submitted on 1 Mar 2021

HAL is a multi-disciplinary open access archive for the deposit and dissemination of scientific research documents, whether they are published or not. The documents may come from teaching and research institutions in France or abroad, or from public or private research centers.
L'archive ouverte pluridisciplinaire HAL, est destinée au dépôt et à la diffusion de documents scientifiques de niveau recherche, publiés ou non, émanant des établissements d'enseignement et de recherche français ou étrangers, des laboratoires publics ou privés. 


\title{
Effect of aging temperature on a thermoset-like novel acrylic thermoplastic composite for marine vessels
}

\author{
Haithem Bel Haj Frej ${ }^{1}$, Romain Léger ${ }^{1}$, Didier Perrin², Patrick Ienny ${ }^{1}$ \\ ${ }^{1}$ LMGC, IMT Mines Ales, Univ Montpellier, CNRS, Ales, France \\ ${ }^{2}$ Polymers Composites and Hybrids (PCH), IMT Mines Ales, Ales, France
}

Abstract

This work aims at evaluating the durability of a carbon fibre reinforced thermoplastic composite under different aging conditions. The absorption and desorption of deionised water in carbon fibre (CF) reinforced Elium composite material were measured gravimetrically over two different temperatures. Water uptake experimental data were fitted to a Langmuir type diffusion model in order to identify and compare diffusion parameters and kinetics and to evaluate their dependence to aging conditions. It was found that the temperature increase had a significant effect only on saturation water uptake. Water desorption after aging was modelled accurately using Fick's law and slight differences were found between model parameters. The effect of hydrothermal aging conditions and their reversibility were then evaluated by static and vibratory mechanical analysis. Results showed a slight and quasi-reversible reduction of longitudinal properties compared to shear properties at moderate aging temperature. While for higher aging temperature, the impact was found to be more significant and permanent on mechanical in-plane properties. Furthermore, static and modal results are confirmed by dynamic mechanical analysis, where the behaviour of studied material is differently affected by aging temperature, with a considerable increase in dried materials glass transition temperature.

Keywords

Carbon fibre; Thermoplastic resin; Hydrothermal aging; Durability; Mechanical properties

\section{Introduction:}

Since the late 1950s, composite materials have been widely in use in marine construction. Nowadays, sailing and motor boats for recreational and sports use are the products of a dynamic and competitive sector, with more than 3600 companies all over Europe, and more than 52k new boats produced in France in $2017^{~}{ }^{1}$. In addition to lightweight and corrosion resistance advantages, the use of fibrereinforced materials makes it possible to produce parts of complex shapes. Therefore, every year, around 12,000 thermoset-based boats reach their end-of-life in French ports, with nearly no eco-friendly valorisation solution known, except landfilling or incineration. In addition to environmental considerations, the increasingly demanding legislation and new European directives make it more than urgent to find a lasting solution for materials for marine use, more specifically for recreational boat construction. In the last few decades, thermoplastic polymers began to find application in marine environment as a substitution to widely used thermoset matrix ${ }^{2}$. A newly developed low-viscosity liquid 
thermoplastic resin from Arkema is being developed for a range of technical use such as wind energy and marine transport industry. Fibre reinforced Elium composites can be proceeded by resin infusion method alike their thermoset counterparts. Therefore, a possible substitution of the widely used thermoset resin by the novel recyclable acrylic resin in marine application may be possible, as far as the substitute presents similar or better durability along service-life. In order to study the durability and predict the lifespan of materials, accelerated aging tests could be conducted under various environments depending on the exposure of the material, including hydrothermal aging, in which the degree of aging is determined via temperature, time, and water ingress. According to the literature, physical and chemical aging are the most common involved mechanisms ${ }^{3,4}$. Physical aging is reversible and takes place in materials exposed to high temperatures for prolonged duration with a possible alteration in thermal and mechanical properties, whilst chemical aging is irreversible and involves chain scission and permanent degradation ${ }^{5}$.

This study focuses on composites for marine vessels, which operate in harsh wet environments with various and coupled loads and stresses. The knowledge of water diffusion kinetics and materials mechanical properties is essential in order to evaluate their durability. Diffusion of water in polymer matrix composites has been extensively studied in the literature ${ }^{6-8}$. Fick's second law of diffusion is the mostly used model for moisture uptake and diffusion parameters identification from gravimetric tests 9 . In case of anisotropic composites, water diffusion depends on several parameters such as reinforcement type, morphology and geometry but also on aging environment and conditions. Depending on aging conditions, composites may exhibit a non-reversible damage generally due to physico-chemical degradation and its explicit numerical modelling becoming complex, thus the classic Fickian model is not adequate. Several authors proposed numerical models, generally derived from Fick ${ }^{10,11}$ or Langmuir 12,13 theories. Other non-empirical modelling of water absorption kinetics induced by chemical reactions 14 and wicking mechanisms ${ }^{15,16}$. The evolution of mechanical properties is generally monitored when absorption and subsequent desorption studies are conducted in order to evaluate aging effects on studied materials ${ }^{17,18}$. Thermoset reinforced composites durability has been widely studied in the literature in terms of mechanisms and consequences of water absorption. In order to switch to thermoplastic polymers, durability has to be investigated. Only few works are already available on some grades of thermoplastic Elium. Davies et al. ${ }^{19}$ studied aging mechanism of acrylic Elium 190 reinforced glass and carbon fibres. Even if a slight drop of mechanical properties was observed after one year of immersion in seawater at $60{ }^{\circ} \mathrm{C}$, material properties were recovered after drying. Their fatigue behaviour is also at least as good as their glass fibre/epoxy counterparts ${ }^{20}$. Nash et al. studied the effect of environmental conditioning in water and diesel fuel on the interlaminar shear and dynamic mechanical properties of glass fibre/Elium 150 composites compared to other thermoset matrix composites ${ }^{21}$. Results showed that acrylic and epoxy composites had similar properties at dry condition, but the effect of water absorption was more significant on Elium reinforced composites ${ }^{22}$.In these results, only diffusion parameters of non-reinforced matrix were given by Davies et al. ${ }^{19}$, and no data on water absorption 
curves or diffusion coefficients were published. A further study by Chilali et al. found comparable mechanical properties evolution of natural flax fibre reinforced Elium 150 and epoxy composites in dry and wet conditions ${ }^{23}$.

In this work, accelerated aging test were performed on neat Elium 188-O resin and its carbon fibre reinforced Elium 188-O composite at two different aging temperatures. Diffusion coefficients and other model parameters were identified and their dependency to the aging conditions was evaluated. Tensile tests were carried out in order to investigate the impact of water sorption and desorption on mechanical properties. In addition, modal analysis was performed to follow the evolution of dynamic elastic modulus during aging and drying steps. Finally, dynamic mechanical analysis allowed the comparison of thermo-mechanical properties of dry, wet and re-dried materials.

\section{Materials and manufacturing processes}

\subsection{Materials}

The materials under investigation in this study were carbon fibre (CF) reinforced acrylic laminates, comprising four plies of stitched biaxial carbon fabric Cbx600 24 K T620 from Sicomin. Fibres in $+45^{\circ}$ and $-45^{\circ}$ directions and textured polyester stitching account for 309,309 and $9 \mathrm{~g} / \mathrm{m}^{2}$, respectively for a total areal weight of $627 \mathrm{~g} / \mathrm{m}^{2}$. The compatibility of the fabric is for general use like epoxy, polyester, vinylester, and phenolic resin and no special sizing for acrylic resin is used due to the limited availability of acrylic sized fabric. The acrylic resin used is Elium 188-O supplied by Arkema. Its formulation given by the manufacturer shows that the resin is mainly composed by methyl-methacrylate monomer (70-90 $\%)$ with citral $(\leq 5 \%)$ and other copolymers and additives. A Perkadox CH-50X dibenzoyl peroxide (BPO) initiator from AkzoNobel is used to initiate the radical polymerisation of the polymer, followed by an exothermic peak. Data from relevant datasheet and literature of physical and mechanical properties of neat Elium 188-O resin are reported in Table 1.

Table 1: Mechanical and thermomechanical properties of Elium 188-O neat resin at $25{ }^{\circ} \mathrm{C}$ with $3 \%$ of BPO initiator ${ }^{24,25}$

\begin{tabular}{ll}
\hline Properties & Elium 188-O \\
\hline Viscosity $(\mathrm{mPa} . \mathrm{s})$ & 100 \\
Density $\left(\mathrm{g} / \mathrm{cm}^{3}\right)$ & 1.2 \\
Peak time (minutes) & 55 \\
Glass transition temperature $\mathrm{T}_{\mathrm{g}}\left({ }^{\circ} \mathrm{C}\right)$ & $109^{*}$ \\
Tensile Strength $(\mathrm{MPa})$ & 76 \\
Tensile Modulus $(\mathrm{GPa})$ & 3.3 \\
Tensile Deformation $(\%)$ & 6 \\
Flexural Strength $(\mathrm{MPa})$ & 130 \\
Flexural Modulus $(\mathrm{GPa})$ & 3.25 \\
\hline${ }^{*}$ Value of measured Tg by differential scanning calorimetry $(D S C)$
\end{tabular}

\subsection{Manufacturing processes}


Casting method was used to produce neat resin samples. Elium resin and BPO initiator were manually mixed in a weight ratio of $2 \%$, then the mixture was casted vertically between two rectangular thick glass plates covered with Teflon sheet to ensure demoulding. The $4 \mathrm{~mm}$ thickness resin plates hereby casted were left to polymerize for 24 hours at room temperature in the closed mould with no further post-curing or thermal treatment. To produce composite laminates, liquid composite moulding method corresponding of vacuum assisted resin infusion process is used. Laminates with stacking sequences of $[0 / 90]_{4}$ and $[+45 /-45]_{4}$ were prepared. For each plate, four layers of fabric were cut and weighed, then the infusion layout was prepared while insuring no leak. Once the resin flow achieved the end of the fabric stack, resin inlet and vacuum outlet were closed. The infused plates were left to polymerize at room temperature for 24 hours, and no post-curing of infused composite plates was performed as for neat resin plates. The average thickness of final composite laminates is around $2.5 \mathrm{~mm}$.

\subsection{Preparation of test specimen}

Specimens were cut from the prepared laminates and casted neat resin plates using a water-lubricated diamond-coated circular saw in accordance with specific test standards. All cut specimens were then conditioned in a convection oven at $40^{\circ} \mathrm{C}$ and less than $15 \%$ of relative humidity $(\mathrm{RH})$ to ensure a free moisture state before testing. In order to assess the quality of produced composite plate, fibre, matrix and void volume fractions were calculated using density measurement performed on an AccuPyc 1330 gas pycnometer from Micromeritics using helium. For this purpose, rectangular samples were cut at random locations on the plate. Knowing the densities of different constituent phases, as well as the fabric areal weight, fibre and matrix volume fractions are calculated and thus void volume fraction is concluded using a weighing method inspired from ASTM D 3171 - 99 and as presented by Cadu et al. ${ }^{26}$. The calculated volume fractions results are given in Table 2 .

Table 2: Constituent volume fractions of Elium 188-O / CF laminates

\begin{tabular}{lcccc}
\hline Properties & $\begin{array}{c}\text { Fibre volume } \\
\text { fraction } v_{f}\end{array}$ & $\begin{array}{c}\text { Matrix volume } \\
\text { fraction } v_{m}\end{array}$ & $\begin{array}{c}\text { Void volume } \\
\text { fraction } v_{v}\end{array}$ & $\begin{array}{c}\text { Fibre weight } \\
\text { fraction }\end{array}$ \\
\hline Measurement & $61(1.78)$ & $35.1(1.92)$ & $3.8(1.27)$ & $71.2(0.51)$ \\
\hline Standard deviations are given between parentheses & & &
\end{tabular}

\section{Experimental methods}

\subsection{Conditioning and accelerated hydrothermal aging}

Dry neat resin and composite samples were immersed in deionised water at two distinct temperatures: $40{ }^{\circ} \mathrm{C}$ and $70{ }^{\circ} \mathrm{C}$. The choice of deionised water is motivated by its availability in the laboratory and also by its known aggressiveness on the polymer and composites in terms of diffusion rate and its consequences on the properties of the materials, compared to composites aged in sea water ${ }^{27,28}$. Immersion temperatures were chosen to accelerate water diffusion kinetics while being far enough from 
glass transition temperature of both neat Elium resin and its fibre reinforced composite. Many techniques are suitable for measuring penetrant uptake, including laser interferometry, Raman spectroscopy, Fourier transform infrared (FTIR) spectroscopy and nuclear magnetic resonance imaging, among others ${ }^{29-34}$. The most common technique, due to its simplicity and versatility, is gravimetric sorption ${ }^{35}$. This latter involves exposing the specimen to water and monitoring the change in its mass with time. All surface water was removed from the sample prior to weighing and immersed coupon weight was monitored using a $\pm 0.1 \mathrm{mg}$ accurate scale (Sartorius Secura 225D-1S) according to ASTM D 5229/D $5229 \mathrm{M}$ - 92 standard specifications. Average moisture content $M_{t_{-} \exp }(\%)$ was taken as the ratio of the mass of absorbed water to the weight of oven-dry material and expressed as given by Equation 1:

$$
M_{t_{-} \exp }(\%)=\frac{W_{i}-W_{0}}{W_{0}} \times 100
$$

Equation 1

where $W_{i}$ is the specimen mass and $W_{0}$ is the oven-dry specimen mass. Water sorption is regularly monitored during immersion in both temperatures, and then water content is reported in a graph as function of a square root of time. When equilibrium plateau is achieved, aged samples were removed from the bath, half of them was tested wet, and the other half was dried in an oven at $40{ }^{\circ} \mathrm{C}$. Here also, the weight loss due to water desorption was monitored by gravimetric analysis until reaching and effective equilibrium state. Mechanical properties were determined in the dry state in order to assess reversibility of aging mechanism. A scheme of the proposed aging protocol is presented in Figure 1.

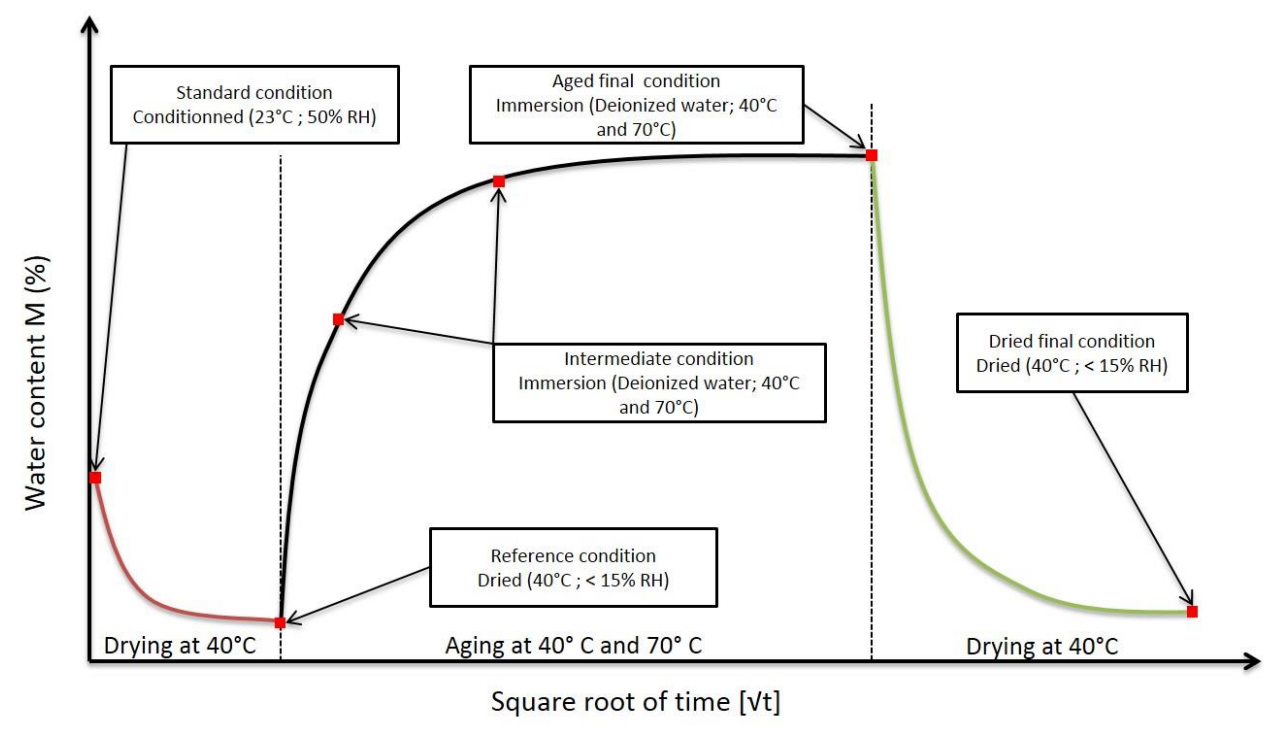

Figure 1: Aging methodology scheme

\subsection{Tensile testing}

Longitudinal and off-axis tensile tests were conducted in accordance with the ISO 527-4 standard requirement on an MTS Criterion C45.105 tensile machine equipped with a $100 \mathrm{kN}$ load cell. Composite sample dimensions were $250 \mathrm{~mm}$ length, $25 \mathrm{~mm}$ width and around $2.5 \mathrm{~mm}$ thickness. After surface sanding and cleaning, aluminium tabs $\left(50 \times 25 \times 2 \mathrm{~mm}^{3}\right)$ were bonded to the tests specimens using 
cyanoacrylate-based Loctite Super Glue 3 adhesive. Test specimens were then painted and speckled in order to use digital image correlation to assess the evaluation of the in-plane strain tensor ${ }^{36}$. The optical extensometer used is a high resolution camera set in front of the specimen. Images from the camera and load from the tensile device are simultaneously recorded in a way that for each image there is a unique load value using LabVIEW software. All tensile tests were carried out at a constant crosshead speed of $1 \mathrm{~mm} / \mathrm{min}$ at unaged, aged at both temperatures and dried final states until breaking according to the protocol presented by Figure 1. Young's modulus was calculated by the means of linear regression between 0.05 and $0.25 \%$ strain interval on at least 5 samples in each case.

\subsection{Modal analysis}

It is a non-destructive test allowing the measurement of Eigen modes of a structure. Each mode is defined by a frequency, modal damping and a mode shape. These modes are directly related to the stiffness, density and boundary conditions of the structure. Using a modal analysis software, the dynamic properties can be estimated from the frequency response function (FRF) ${ }^{37}$. In practical, tensile samples of $250 \mathrm{~mm} \times 25 \mathrm{~mm}$ are suspended by elastics in order to consider free-free boundary conditions. An impact hammer (Kistler 9722A2000) is used to apply forced vibration of the specimen and generate a pulse. An accelerometer, placed at the opposite end of the test sample, records the impulse response. Thereby, signals acquisition enables to calculate FRF by means of Ffast Fourier transform (FFT). The dynamic Young's modulus can be then computed using analytic model for simple geometry, or finite element numerical model for complex ones. In order to quantify the dynamic elastic modulus of the structure, the resonance frequency of the first tension-compression mode is measured by means of ModalVIEW software. Taking into account samples dimensions, the dynamic modulus is measured as follow:

$$
E=4 \times \rho \times L^{2} \times f^{2}
$$

Equation 2

with $\rho$ is the material density, $\mathrm{L}$ the length and $\mathrm{f}$ its resonance frequency.

During aging, tensile samples were removed from the conditioning bath, wiped off of surface water, weighed and then modal analysis was conducted.

\subsection{Dynamic mechanical analysis (DMA)}

Tests were performed on composite and neat resin specimens having dimensions of $(80 \times 10 \times 2.5)$ and $(80 \times 10 \times 4) \mathrm{mm}^{3}$, respectively. The dual cantilever beam testing mode is used accordingly to ASTM D5418-15 on a METRAVIB DMA50 machine. The tested specimens were cut in the longitudinal and off-axis directions of the fibres. Preliminary tests were conducted in order to define relevant test parameters (temperature range, frequency and dynamic displacement) and to validate the linear response of the studied materials according to selected parameters. A $5 \mathrm{~Hz}$ frequency, $10 \mu \mathrm{m}$ dynamic strain amplitude and temperature range from 50 to $160{ }^{\circ} \mathrm{C}$ at a heating rate of $3{ }^{\circ} \mathrm{C} / \mathrm{min}$ were finally chosen. The complex dynamic modulus $E^{*}$ and loss factor $\eta$ can be written as: 


$$
E^{*}=E^{\prime}+i E^{\prime \prime}
$$

Equation 3

and

$$
\eta=\tan (\delta)=\frac{E^{\prime \prime}}{E^{\prime}}
$$

Equation 4

in which $E^{\prime}$ is the storage modulus (real part) showing material elastic behavior, and $E^{\prime \prime}$ is the loss modulus (imaginary part), which is related to viscoelastic behaviour. The loss factor $\eta$ is also called damping factor. It is related to the amount of energy that the material can dissipate due to the viscous behaviour ${ }^{37}$.

\section{Results and discussion}

\subsection{Hydrothermal aging}

\section{Water sorption}

Samples of both neat Elium resin and carbon fibre reinforced composite were initially conditioned at 40 ${ }^{\circ} \mathrm{C}$ in a convection oven in order to quantify the already present moisture inside studied samples prior to hydrothermal aging test. Regular weighings of mass loss were performed until reaching an effective equilibrium state, in which the average mass loss between two successive measurements was less than $0.01 \%$. At this stage, Elium neat resin samples have lost around $0.25 \%$ from their initial weight, whereas $\mathrm{CF} /$ Elium composites lost around $1 \%$ of their weight. All next measurements and results will be referred to this moisture-free state as samples at reference condition according to aging scheme presented in Figure 1.
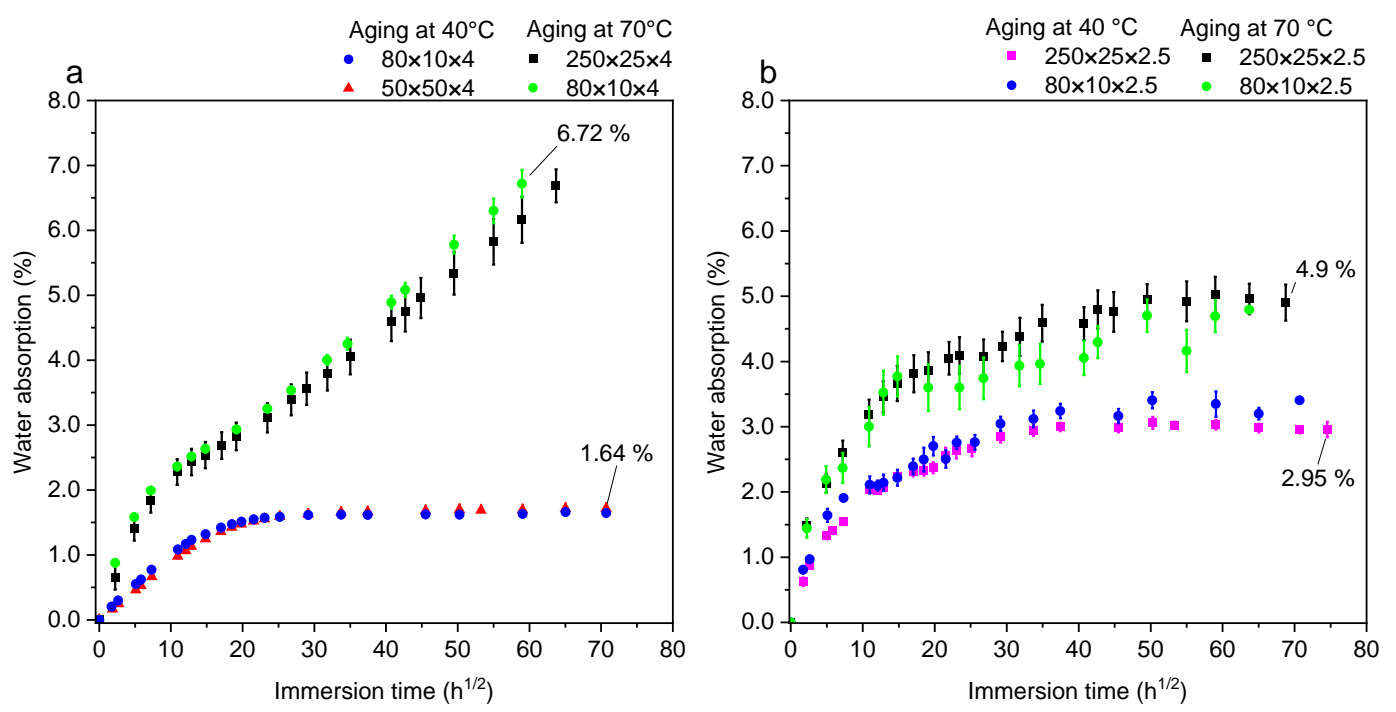

Figure 2: (a) Elium neat resin and (b) carbon fibre ([0/90] $)$ reinforced Elium composite water uptake curves measured as \% of weight increase vs. time in square root of hours

Elium neat resin samples immersed in deionised water at $40{ }^{\circ} \mathrm{C}$ and $70{ }^{\circ} \mathrm{C}$ water uptake curves are shown in Figure 2.a. For samples immersed at $40{ }^{\circ} \mathrm{C}$, water sorption profile is Fickian-like for samples with different geometries. Water content increases linearly before forming a concave region to the abscissa 
characterized by a slower diffusion rate until reaching a saturation plateau at around $M_{t_{-} \text {exp }}=1.66 \%$. At $70{ }^{\circ} \mathrm{C}$, a two-step non-Fickian aging behaviour is observed: A first linear part up to 64 hours of immersion $\left(8 \mathrm{~h}^{1 / 2}\right)$ is followed by significant decrease in diffusion rate observed by the change of the slope. No saturation plateau is reached after 150 days of immersion. In the literature, such a diffusive behaviour accounts for the case of rapid increase in the fluid content, followed by a decrease in the diffusive rate, while the weight gain never reaches equilibrium, as with two-phase diffusion ${ }^{7}$. Furnished information from the manufacturer about the composition of the supplied resin showed that it consists of around $50 \%$ to $85 \%$ of methyl methacrylate (MMA) monomer. In analogy with poly(methylmethacrylate) PMMA polymer aged at high temperatures, the mechanism of water sorption is accelerated and the PMMA chains undergo hydrolysis reactions at the level of the side groups without scission of its macromolecular chain. There is then a change in the polarity of side groups: more polar acid groups replace the initial groups and their formation causes an increase in polymer hydrophilicity 38. A further possible explanation of the typical two-step diffusion for Elium neat resin at $70{ }^{\circ} \mathrm{C}$ may be related to its chemical formulation as it is a mixture of MMA monomer and other copolymers ${ }_{-}^{39}$. Furthermore, samples dimensions do not seem to have significant influence on initial water uptake. Compared to $70{ }^{\circ} \mathrm{C}$ aging plots, water uptake of neat resin at $40{ }^{\circ} \mathrm{C}$ is clearly slower and maximum moisture content at equivalent immersion period is lower. This can be related to thermally induced water diffusion behaviour. In fact, from a chemical point of view, hydrolysis rate is known to be a thermally accelerated reaction that occurs at the level of polymer molecular bonding ${ }_{-}^{14}$. Moreover, it is clear that sample dimensions do not have influence on water uptake in both aging conditions.

With respect to the composite samples (only [0/90]4 lay-up configuration), water uptake vs. square root of immersion time plots are given in Figure 2.bErreur ! Source du renvoi introuvable.. As is the case with neat resin specimens, aged composites samples show different responses when immersed at either $40{ }^{\circ} \mathrm{C}$ or $70{ }^{\circ} \mathrm{C}$. For tensile and DMA samples (i.e. samples of $250 \times 25 \times 2.5 \mathrm{~mm}^{3}$ and $80 \times 10 \times 2.5$ $\mathrm{mm}^{3}$ dimensions) aged at $70{ }^{\circ} \mathrm{C}$, water uptake increases gradually but not linearly with a similar rate until around $14 \mathrm{~h}^{1 / 2}$ (9 days). A significant slowdown in diffusion rate is observed then, with gradually increasing moisture content until reaching an equilibrium plateau at around $M_{t_{-} \text {exp }}=4.9 \%$ after 150 days of immersion. The absence of a clear linear part followed by a saturation plateau suggest that the sorption behaviour is non-Fickian. Regarding aging mechanisms at $40{ }^{\circ} \mathrm{C}$, similarities are found but with a lower moisture content at saturation $(\sim 3 \%)$ for rectangular samples. Moisture uptake linear part in the early immersion stage is rapidly followed by a gradually change in curve slope. At $40{ }^{\circ} \mathrm{C}$, maximum moisture content is reached at lower immersion duration (60 days) compared to results of aging at $70{ }^{\circ} \mathrm{C}$. It is also worth noting that composites samples with different panel sizes absorbed twice more water than neat resin. Regarding significant voids fraction already present in composite materials (Table 2), it is evident that moisture uptake is significantly altered by the presence and the volumetric distribution of voids, particularly at the level of fibre/matrix interface where it is known that the bonding state at that area have significant effect on water diffusion behaviour and mechanisms. ${ }_{-}^{40}$. 


\section{Water desorption}

Moisture content curves of neat resin and composite samples dried at $40{ }^{\circ} \mathrm{C}$ after hydrothermal aging at $70{ }^{\circ} \mathrm{C}$ and $40{ }^{\circ} \mathrm{C}$ are presented in Figure 3. Neat resin samples aged at $70^{\circ} \mathrm{C}$ do not reach saturation plateau as it showed in Figure 2. However, when subjected to drying, the moisture content decreases constantly until reaching an equilibrium around zero water content, suggesting that all absorbed water have been desorbed (Figure 3.a). Excess in desorbed moisture content in neat resin samples was around $0.1 \%$ for samples aged at $40{ }^{\circ} \mathrm{C}$ and $0.2 \%$ for samples aged at $70{ }^{\circ} \mathrm{C}$, which represents respectively $6 \%$ and $3 \%$ of initial moisture content at the end of aging stage. In addition, samples dried after being aged at $70{ }^{\circ} \mathrm{C}$ have a similar length to width ratio and present a similar behaviour.
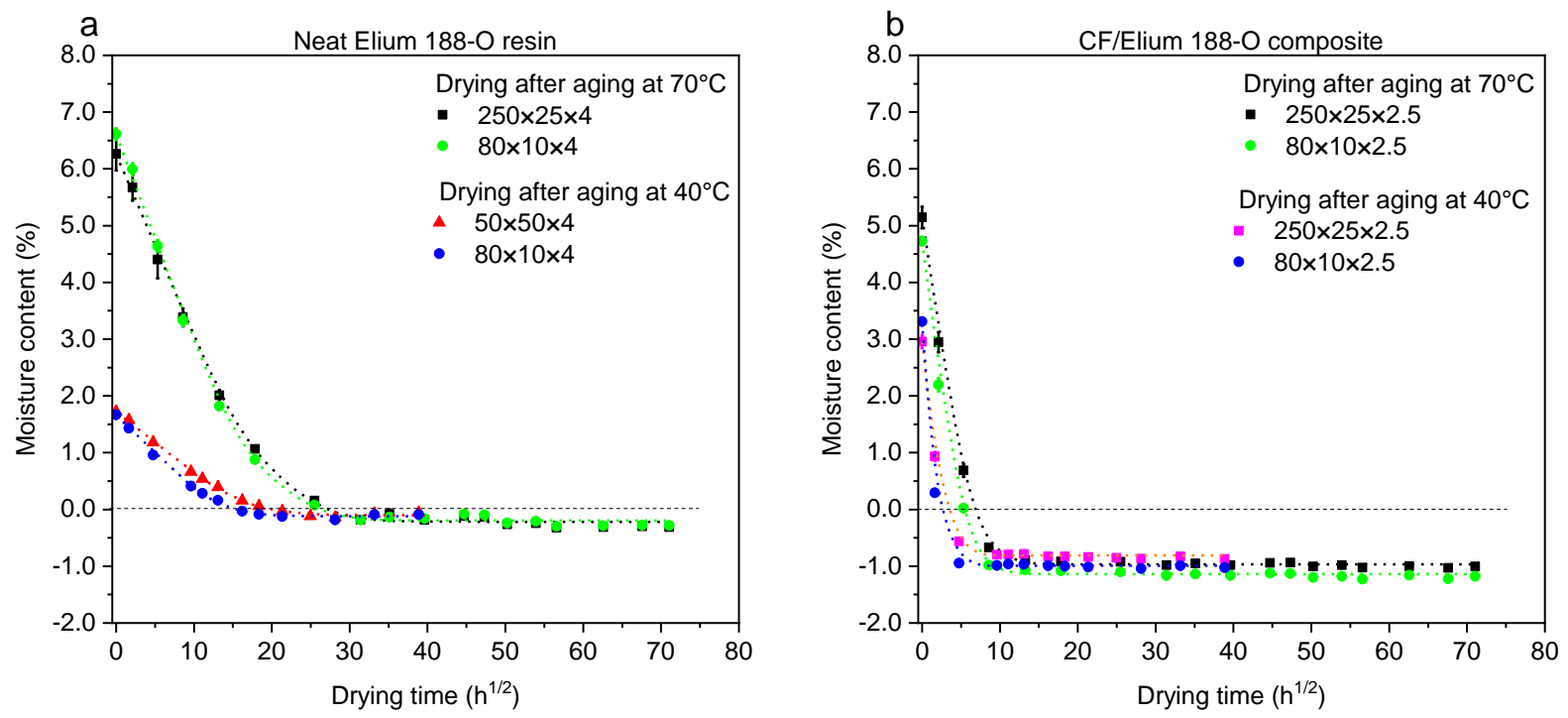

Figure 3: Moisture content vs. drying time of (a) neat resin and (b) $C F\left([0 / 90]_{4}\right)$ reinforced composite dried at $40^{\circ} \mathrm{C}$ after aging. Dashed curves represent Fickian desorption model results.

Composite samples with $[0 / 90]_{4}$ configuration drying results follow a Fickian-like behaviour for any geometry and aging temperature as presented in Figure 3.b. Almost identical mass loss of around 1\% of initial moisture content after aging is found despite the difference found at maximum moisture content at the end of aging at both different temperatures. These observations lead to consider that an irreversible damage occurred during aging of composites independently from aging temperature. A recent published work by Hendlmeier et al. suggests that epoxy sizing on carbon fibre fabric is soluble on methyl methacrylate monomer, and it was removed from fibres surface during processing and before complete polymerisation of MMA based polymer ${ }^{41}$. A leaching of unreacted and solubilised species may be the cause of this excess in weight loss level no matter what the aging temperature is.

\subsection{Modelling of sorption and desorption behaviour}

\subsubsection{Fickian sorption and desorption models}

In order to better understand and to propose a comparison of diffusion kinetics in both resin and composite material subjected to hydrothermal aging at two different temperatures, analytic models are 
proposed to fit experimental findings. The most common approach to model moisture sorption (and desorption) is Fick's law. It suggests that the mass of absorbed water increase linearly with square root of time and then gradually slows until reaching an equilibrium moisture content. As recorded sorption and desorption results are geometrically independent, the hypothesis of isotropic large plane samples can be considered. Therefore, moisture diffusion is considered as one-dimensional phenomena, i.e. water only diffuses through the thickness. It is worth noting that Fick's second law can be applied for simple diffusion moisture process, in which chemical reactions between polymer and water molecules are not considered. The solution of moisture concentration over the thickness of the material, can be written as:

$$
\frac{M_{t}}{M_{\infty}}=1-\frac{8}{\pi^{2}} \sum_{n=0}^{\infty} \frac{1}{(2 n+1)^{2}} \exp \left(\frac{-\pi^{2} D t(2 n+1)^{2}}{h^{2}}\right) \quad \text { Equation } 5
$$

Where $M_{t}$ is the water content at time t, $D$ is diffusion coefficient and $M_{\infty}$ is the water content at equilibrium. In the same context, desorption process in the case of initially saturated samples can be modelled using Fick's law in conjunction with the adequate boundary conditions. The integration of the solution of the differential equation set for time $t$ and for spatial coordinate $x$ over the thickness of a plate is given as:

$$
\frac{M_{t}-M_{r}}{M_{\infty}-M_{r}}=\frac{8}{\pi^{2}} \sum_{n=0}^{\infty} \frac{1}{(2 n+1)^{2}} \exp \left(\frac{-\pi^{2} D_{d} t(2 n+1)^{2}}{h^{2}}\right) \quad \text { Equation } 6
$$

Where $M_{r}$ is the residual mass fraction at the equilibrium. In order to identify unknown diffusion and desorption coefficient from Equation 5 and Equation 6, an optimisation approach relying on the construction of an objective function $q$ is given by:

$$
q=\sum_{i}\left[M_{t_{-} \exp }\left(t_{i}\right)-M_{t}\left(t_{i}\right)\right]^{2}
$$

Equation 7

With $M_{t}\left(t_{i}\right)$ is the analytical moisture content calculated from Equation 5 and Equation 6 at time $t_{\mathrm{i}}$ and $M_{i}$ is the experimental water content extracted from the gravimetric curve. Minimizing the function $q$ allows the identification of different unknowns by adjusting the diffusion curve according to Fick's law solution to the experimental data. Optimization is carried out with Matlab ${ }^{\circledR}$ software using a PSO (Particle Swarm Optimization) metaheuristic routine.

\subsubsection{Non-Fickian water diffusion}

In case of anomalous water content evolution against square root of time, the use of Fickian model is no longer appropriate and can lead to less reliable estimation of diffusion parameters and local concentration field. The deviation from the Fickian diffusion model can be related to either physical or chemical degradation that occurs in aged materials, especially in harsh aging conditions ${ }^{42}$. Further explications of anomalous diffusion process are related to manufacturing quality, especially the presence of voids in bulk matrix or at fibre/matrix interface as well as the quality of fibre/matrix bonding. Thomason showed that porosity and voids can significantly increase absorption rate and saturation level 
of composite laminates, even at low volume contents ${ }^{40}$. Several models were proposed in the literature in order to quantify anomalous and non-Fickian responses of aged materials like time-dependent diffusion coefficient model ${ }^{43,44}$, concentration-dependent diffusion coefficient model ${ }^{45}$, dual Fickian model ${ }^{10}$, etc. Furthermore, Carter and Kibler ${ }^{12}$ have developed a Langmuir type sorption model in order to better understand, with reliable manner, non-linear diffusion processes. Moisture uptake curves, represented as a function of square root of time, are divided into two successive sub-behaviours: The first linear "Fickian-like" part described by a constant diffusion coefficient is transformed at later times to lower, but non-zero, gradient. This model is based on a hypothesis of the existence of two "types" or "states" of absorbed water: Bound water and free (i.e. mobile) water. A probability per unit time $\gamma\left[\mathrm{s}^{-1}\right]$ is associated to the probability of mobile water molecules to become bound and $\beta\left[\mathrm{s}^{-1}\right]$ is probability of already bound molecules to break the bonding and become free. If we consider $n(t)$ mobile water molecules content and $N(t)$ bound water molecules content per unit volume at time $\mathrm{t}$, at saturation we obtain:

$$
\gamma n_{\infty}=\beta N_{\infty} \quad \text { Equation } 8
$$

In the literature, several works have tried experimentally to bring out the existence of bound and mobile water in aged materials using different techniques like infrared spectroscopy ${ }^{46}$, nuclear magnetic resonance (NMR) ${ }^{29}$ and differential scanning microscopy ${ }^{47}$. When analysing NMR peaks, Popineau et al ${ }^{29}$ found that water diffusion process can be presented as a four steps process: Initially, molecular water with strong interactions diffuses into the polymer as mobile molecules until saturation of interaction sites of polymer. When a quasi-equilibrium is reached, water absorption begins again, but since water molecules have already occupied microvoids, relatively large clusters are formed. These clusters are with lower inertia, forming then bound water. From a mathematical point of view, the Carter \& Kibler model is based on the assumption that the diffusion of mobile molecules conforms to simple diffusion theory modified by sources and sinks ${ }^{12}$. In one-dimensional case, molecular densities at position $x$ and time $t$ satisfy the system of equations:

$$
\left\{\begin{array}{c}
D_{\gamma} \frac{\partial^{2} n}{\partial x^{2}}=\frac{\partial n}{\partial t}+\frac{\partial N}{\partial t} \\
\frac{\partial N}{\partial t}=\gamma n-\beta N \\
c=n+N
\end{array}\right.
$$

Equation 9

It can be seen from Equation 9 that Fick diffusion model is a specific case of two stage Carter and Kibler diffusion, where $\mathrm{N}=0$. The total water uptake $M_{t}$ after exposure time $\mathrm{t}$ in an initially dry one-dimensional specimen is given by: 


$$
\begin{gathered}
M_{t}=M_{\infty}\left\{\left(\frac{\beta}{\gamma+\beta}\right) e^{-\gamma t}\left(1-\frac{8}{\pi^{2}} \sum_{n=0}^{\infty} \frac{1}{(2 n+1)^{2}} \exp \left(\frac{-\pi^{2} D_{\gamma} t(2 n+1)^{2}}{h^{2}}\right)\right)\right. \\
\left.+\left(\frac{\beta}{\gamma+\beta}\right)\left(e^{-\beta t}-e^{-\gamma t}\right)+\left(1-e^{-\beta t}\right)\right\}
\end{gathered}
$$

Equation 10

In order to identify separately the contribution of both free and bound water to the total moisture content, a solution to Equation 9 mentioned above with the introduction of an integration factor as it is done in ${ }^{29}$ leads to:

$$
\left\{\begin{array}{c}
\frac{n(t)}{M_{\infty}}=\frac{\beta}{\gamma+\beta}\left\{1-\frac{8}{\pi^{2}} e^{-\kappa t}\right\} \\
\frac{N(t)}{M_{\infty}}=\frac{\gamma \beta}{\gamma+\beta} e^{-\beta t}\left\{\frac{1}{\beta}\left(e^{\beta t}-1\right)-\frac{8}{\pi^{2} \kappa}\left(e^{-\kappa t}-1\right)\right\} ; \beta, \gamma \ll \kappa
\end{array}\right.
$$

Equation 11

With $\kappa=\frac{\pi^{2} D_{\gamma}}{h^{2}}$ and $M_{\infty}$ is the maximum moisture content.

\subsubsection{Neat resin diffusion modelling}

In Figure 4, experimental gravimetric data of aged neat resin samples are compared to 1D Fick model in the case of samples aged at $40{ }^{\circ} \mathrm{C}$ and to the Carter and Kibler model for samples aged at $70{ }^{\circ} \mathrm{C}$. Only one specimen size results are illustrated here for each aging temperature for brevity, but detailed results are given in Table 3. In Figure 4.a, experimental data recorded from DMA samples perfectly fit to the Fick model with a saturation plateau found at $1.67 \%$. In addition, identified diffusion coefficients from both DMA and square samples are relatively close (3.4 E-12 m²/s and $2.41 \mathrm{E}-12 \mathrm{~m}^{2} / \mathrm{s}$, respectively). In this case, it is unnecessary to fit Elium resin results to the Carter and Kibler model, since it is assumed that for a Fickian diffusion, water present in the material is only in the free state, Fick model is hence a particular case from Carter \& Kibler model. Figure 4.b depicts the comparison of experimental results of square Elium resin samples aged at $70{ }^{\circ} \mathrm{C}$ against Carter and Kibler model. As described in the previous section, water uptake level rises linearly until around $2.2 \%$ then a change in the curve slope is observed. Mass gain continues to raise linearly without reaching any saturation plateau or a second slope change. Carter \& Kibler model parameters are identified by the means of Equation 10 and the PSO optimisation algorithm in order to better fit model to experimental results. The contribution of water in the "free" state is represented by dashed green curve with a Fickian-like behaviour. The initial part of the curve allows the identification of the diffusion coefficient $D_{\gamma}$, while the pseudo-saturation level represents the moisture equilibrium state of the free water contribution part. The second part of the curve represents the bound water contributions to the total water uptake. Bound water volume content begin to rise slowly in the early immersion duration. At the equivalent time, which free water contribution curve reached the equilibrium level, bound water curve slope begins then to gradually rise over immersion time. Tensile and DMA samples present comparable identified model parameters, all given in Table 3. It is worth noting that diffusion coefficients are higher for samples aged at higher temperatures. In the case of aging at $70{ }^{\circ} \mathrm{C}$, the identified probabilities are geometrically independent. 
Moreover, the probabilities of mobile water molecules to become bound $(\gamma)$ are higher than the probabilities of already bound molecules to become free $(\beta)$.
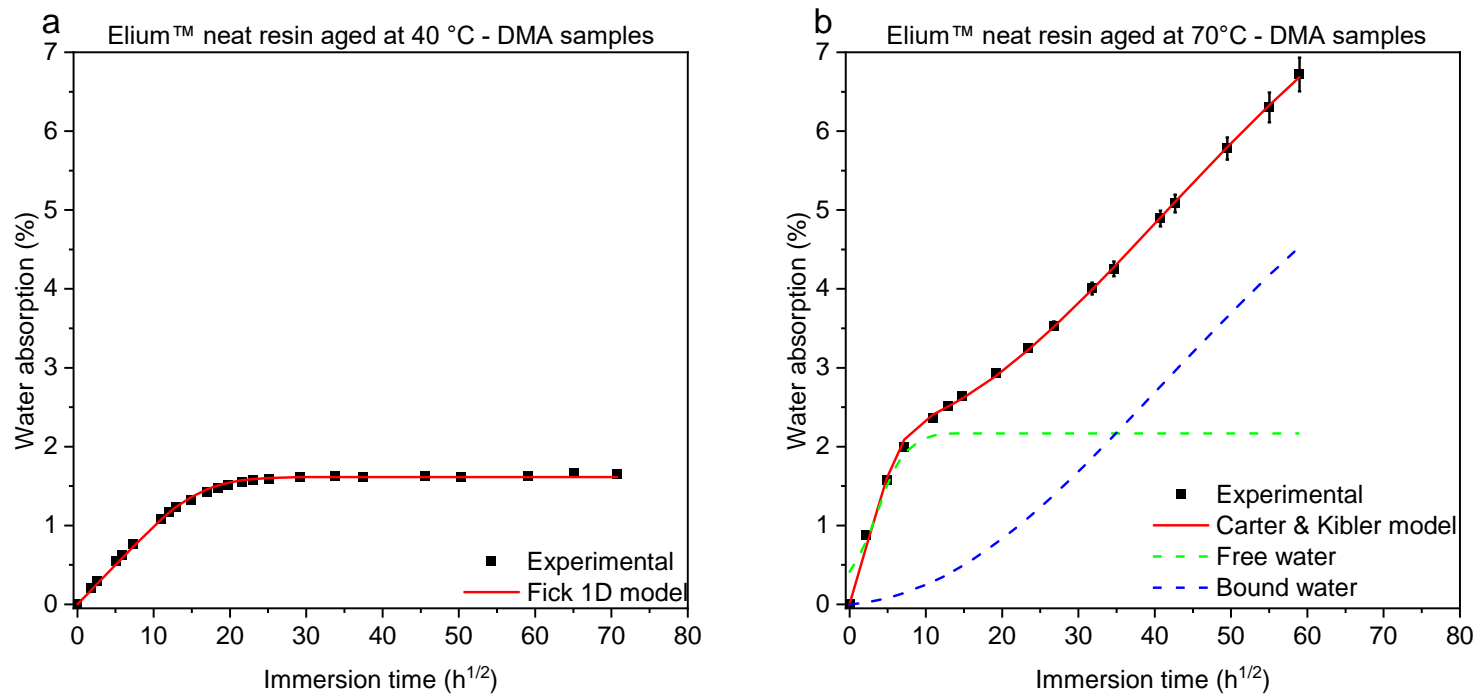

Figure 4:Elium 188-O neat resin experimental results versus numerical models for DMA samples

aged at : a) $40^{\circ} \mathrm{C}$ and $\left.b\right) 70^{\circ} \mathrm{C}$

\subsubsection{Composite diffusion modelling}

Regarding composite samples, an overall similar behaviour as neat resin is observed with a free water content presenting a Fickian behaviour, which saturates at the level of pseudo-equilibrium state identified by a change in the slope of water absorption curve. On the other hand, bound water fraction evolution is slower than free water one, which may be responsible of the gradual increase of water content and the delay to reach effective equilibrium compared to a Fickian-like diffusion. Furthermore, the objective function is minimized in order to identify Carter and Kibler model parameters, and the found theoretical curves for all temperatures and sample dimensions (only [0/90 $]_{4}$ tensile samples are presented in Figure 5) are in a good agreement with experimental findings. For tensile and DMA samples, it was found that diffusion coefficients for samples aged at $40{ }^{\circ} \mathrm{C}$ are slightly higher than for those aged at $70^{\circ} \mathrm{C}$, which is not expected. A postulated explanation is that, at small immersion time, the temperature does not influence water diffusion mechanism, which may be governed by surface porosities and fibre/matrix bonding quality. 

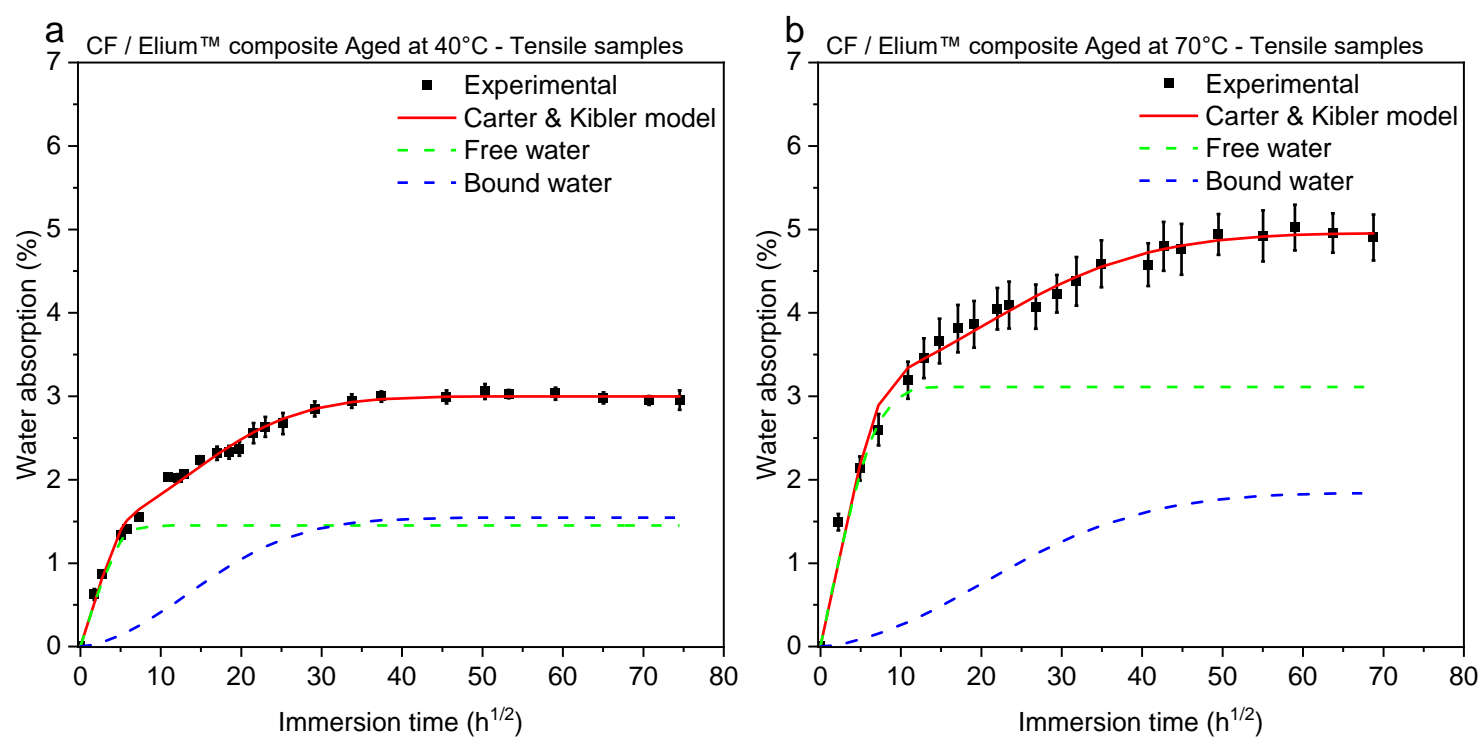

Figure 5: CF / Elium composite experimental aging results versus numerical models for tensile $\left(250 \times 25 \times 2.5 \mathrm{~mm}^{3}\right)$ samples aged at : a) $40{ }^{\circ} \mathrm{C}$ and b) $70{ }^{\circ} \mathrm{C}$

From a literature point of view, both $\beta$ and $\gamma$ probabilities are found to have weak dependency to aging temperature compared to polymer hydrophilicity according to Carter and Kibler's study ${ }^{12}$. Although, Popineau et al. suggested that it is not unreasonable to expect a temperature dependency of the model parameters as it is for the diffusion coefficient. Further findings proved that Carter \& Kibler identified parameters depend strongly on aging conditions such as temperature and relative humidity ${ }^{10}$. In this study, identified probabilities $\beta$ and $\gamma$ from composite samples presented in Table 3 seems to slightly lower with increased temperature, but this evolution is trivial compared to other published results, where $\beta$ and $\gamma$ probabilities are at least 8 times higher when temperature raised from $35^{\circ} \mathrm{C}$ to $60{ }^{\circ} \mathrm{C}{ }^{29}$.

Table 3: Carter \& Kibler model results for neat Elium and CF / Elium composite samples aged at 40 ${ }^{\circ} \mathrm{C}$ and $70{ }^{\circ} \mathrm{C}$

\begin{tabular}{|c|c|c|c|c|c|c|c|c|}
\hline Material & \multicolumn{4}{|c|}{ Elium 188-O resin } & \multicolumn{3}{c|}{ CF / Elium composite } \\
\hline Temperature & \multicolumn{2}{|c|}{$40{ }^{\circ} \mathrm{C}$} & \multicolumn{2}{|c|}{$70{ }^{\circ} \mathrm{C}$} & \multicolumn{2}{c|}{$40{ }^{\circ} \mathrm{C}$} & \multicolumn{2}{c|}{$70{ }^{\circ} \mathrm{C}$} \\
\hline $\begin{array}{c}\text { Sample } \\
\text { dimensions }\end{array}$ & $\begin{array}{c}\text { Square } \\
50 \times 50 \times 4\end{array}$ & $\begin{array}{c}\text { DMA } \\
80 \times 10 \times 4\end{array}$ & $\begin{array}{c}\text { Tensile } \\
250 \times 25 \times 4\end{array}$ & $\begin{array}{c}\text { DMA } \\
80 \times 10 \times 4\end{array}$ & $\begin{array}{c}\text { Tensile } \\
250 \times 25 \times 2.5\end{array}$ & $\begin{array}{c}\text { DMA } \\
80 \times 10 \times 2.5\end{array}$ & $\begin{array}{c}\text { Tensile } \\
250 \times 25 \times 2.5\end{array}$ & $\begin{array}{c}\text { DMA } \\
80 \times 10 \times 2.5\end{array}$ \\
\hline $\mathrm{D}_{\gamma}\left[\mathrm{m}^{2} / \mathrm{s}\right]$ & $2.41 \mathrm{E}-12$ & $3.4 \mathrm{E}-12$ & $1.33 \mathrm{E}-11$ & $1.96 \mathrm{E}-11$ & $1.37 \mathrm{E}-11$ & $1.63 \mathrm{E}-11$ & $6.92 \mathrm{E}-12$ & $5.48 \mathrm{E}-12$ \\
\hline$\beta\left[\mathrm{s}^{-1}\right]$ & - & - & $7.52 \mathrm{E}-8$ & $8.32 \mathrm{E}-8$ & $7.64 \mathrm{E}-7$ & $5.05 \mathrm{E}-7$ & $3.44 \mathrm{E}-7$ & $1.54 \mathrm{E}-7$ \\
\hline$\gamma\left[\mathrm{s}^{-1}\right]$ & - & - & $2.28 \mathrm{E}-7$ & $2.68 \mathrm{E}-7$ & $8.14 \mathrm{E}-7$ & $4.56 \mathrm{E}-7$ & $2.04 \mathrm{E}-7$ & $7.3 \mathrm{E}-8$ \\
\hline $\mathbf{N}[\%]$ & 1.67 & 1.61 & 8.79 & 9.14 & 2.99 & 3.32 & 4.96 & 4.82 \\
\hline
\end{tabular}

\subsubsection{Desorption modelling}

Drying tests were performed after aging in order to elucidate the reversibility of aging mechanisms and their effects on material physical and mechanical properties. Equation 6 represents the solution of the 
numerical model based on Fick's second law of diffusion. As for absorption processes, desorption model best parameters were determined by mean of the optimisation method. In Figure 3, experimental and numerical model curves are both presented, and subsequent identified parameters are reported in Table 4. It is clear that, whatever sample dimensions are, neat resin desorption coefficients are lower than their composite counterparts. However, it seems that the heterogeneity in composite material aids the desorption of water molecules compared to bulk resin samples. It is also worth noting that samples, which have been aged at $40{ }^{\circ} \mathrm{C}$, present relatively higher desorption coefficients compared to samples aged at $70{ }^{\circ} \mathrm{C}$. The negative values of residual weight loss $\mathrm{M}_{\mathrm{r}}$ indicate that permanent degradation other than plasticization took place during aging process. This phenomenon is usually related to the desorption of hydrolysed species and the dissolution and leaching of unreacted monomers. As a consequence, the hypotheses that this excess in desorbed water coming from water already present in the material cannot be adopted, since all samples were dried in the same conditions until an effective equilibrium state prior to aging.

Table 4: Desorption model results for neat Elium resin and CF / Elium composite samples aged at 40 ${ }^{\circ} \mathrm{C}$ and $70{ }^{\circ} \mathrm{C}$ and dried at $40^{\circ} \mathrm{C}$

\begin{tabular}{|c|c|c|c|c|c|c|c|c|}
\hline Material & \multicolumn{3}{|c|}{ Elium 188-O resin } & \multicolumn{3}{c|}{ CF / Elium composite } \\
\hline Temperature & \multicolumn{2}{|c|}{$40{ }^{\circ} \mathrm{C}$} & \multicolumn{2}{c|}{$70{ }^{\circ} \mathrm{C}$} & \multicolumn{2}{c|}{$40{ }^{\circ} \mathrm{C}$} & \multicolumn{2}{c|}{$70{ }^{\circ} \mathrm{C}$} \\
\hline $\begin{array}{c}\text { Sample } \\
\text { dimensions }\end{array}$ & $\begin{array}{c}\text { Square } \\
50 \times 50 \times 4\end{array}$ & $\begin{array}{c}\text { DMA } \\
80 \times 10 \times 4\end{array}$ & $\begin{array}{c}\text { Tensile } \\
250 \times 25 \times 4\end{array}$ & $\begin{array}{c}\text { DMA } \\
80 \times 10 \times 4\end{array}$ & $\begin{array}{c}\text { Tensile } \\
250 \times 25 \times 2.5\end{array}$ & $\begin{array}{c}\text { DMA } \\
80 \times 10 \times 2.5\end{array}$ & $\begin{array}{c}\text { Tensile } \\
250 \times 25 \times 2.5\end{array}$ & $\begin{array}{c}\text { DMA } \\
80 \times 10 \times 2.5\end{array}$ \\
\hline $\mathrm{D}_{\mathrm{d}}\left[\mathrm{m}^{2} / \mathrm{s}\right]$ & $3.13 \mathrm{E}-12$ & $4.95 \mathrm{E}-12$ & $2.2 \mathrm{E}-12$ & $2.57 \mathrm{E}-12$ & $3.49 \mathrm{E}-11$ & $6.43 \mathrm{E}-11$ & $7.55 \mathrm{E}-12$ & $1.06 \mathrm{E}-11$ \\
\hline $\mathrm{M}_{\infty}[\%]$ & 1.72 & 1.66 & 6.26 & 6.61 & 2.95 & 3.31 & 5.14 & 4.72 \\
\hline $\mathrm{M}_{\mathrm{r}}[\%]$ & -0.10 & -0.12 & -0.21 & -0.19 & -0.81 & -0.99 & -0.96 & -1.14 \\
\hline
\end{tabular}

\subsection{Evolution of mechanical properties}

\subsubsection{Longitudinal tensile tests}

Uniaxial tensile tests were carried out on samples at unaged (reference condition), aged (aged final condition at $40{ }^{\circ} \mathrm{C}$ or $70{ }^{\circ} \mathrm{C}$ ) and dried (dried final condition) states. Relative stress-strain curves, presented in Figure 6, have shown a similar fragile-brittle elastic behaviour until failure, with a marked decrease of tensile strength between unaged and aged at both temperatures cases. Figure 7 recapitulates mean values and standard deviation of Young's modulus and ultimate tensile strengths. From Figure 7.a and Figure 7.c, the axial tensile modulus drop is found to be similar but more important for samples aged at $70{ }^{\circ} \mathrm{C}(6.7 \%)$ compared to those aged at $40{ }^{\circ} \mathrm{C}(5.5 \%)$. After drying, the behaviour is quite different: for $40{ }^{\circ} \mathrm{C}$ aged samples, a full recovery of the sample tensile modulus is observed, while specimens aged at $70{ }^{\circ} \mathrm{C}$ exhibit non-reversible degradation of about $17 \%$ compared to reference unaged state. This dissimilar reversibility of aging effects in studied laminates under accelerated aging shows the temperature dependency of the mechanical properties, suggesting that, when immersed at $70{ }^{\circ} \mathrm{C}$, 
composite material exhibits permanent chemical degradation compared to $40{ }^{\circ} \mathrm{C}$ aging condition, during which only reversible plasticization took effect. Furthermore, tensile strength results at different study steps are depicted in Figure 7.b and Figure 7.d. As found for Young modulus, the evolution of the ultimate tensile strength after aging was in the same range. However, results for this aged state were less repeatable, since samples were directly prepared after being extracted from immersion bath and then rapidly tested, which altered the bonding of aluminium tabs and caused their slipping between machine clamps just prior to sample breakage. On the other hand, after drying at $40{ }^{\circ} \mathrm{C}$, a moisture free state is obtained and a partial recovery of ultimate tensile strength is found for samples aged at $40{ }^{\circ} \mathrm{C}$ compared to $70{ }^{\circ} \mathrm{C}$ aged samples, where non reversible permanent degradation took place. Those findings confirm that, when exposed to hydrothermal aging at high temperature, permanent chemical degradations govern the moisture saturated composite laminate response. At lower aging temperature, water absorption effect seems to be partially recoverable after eliminating absorbed water.
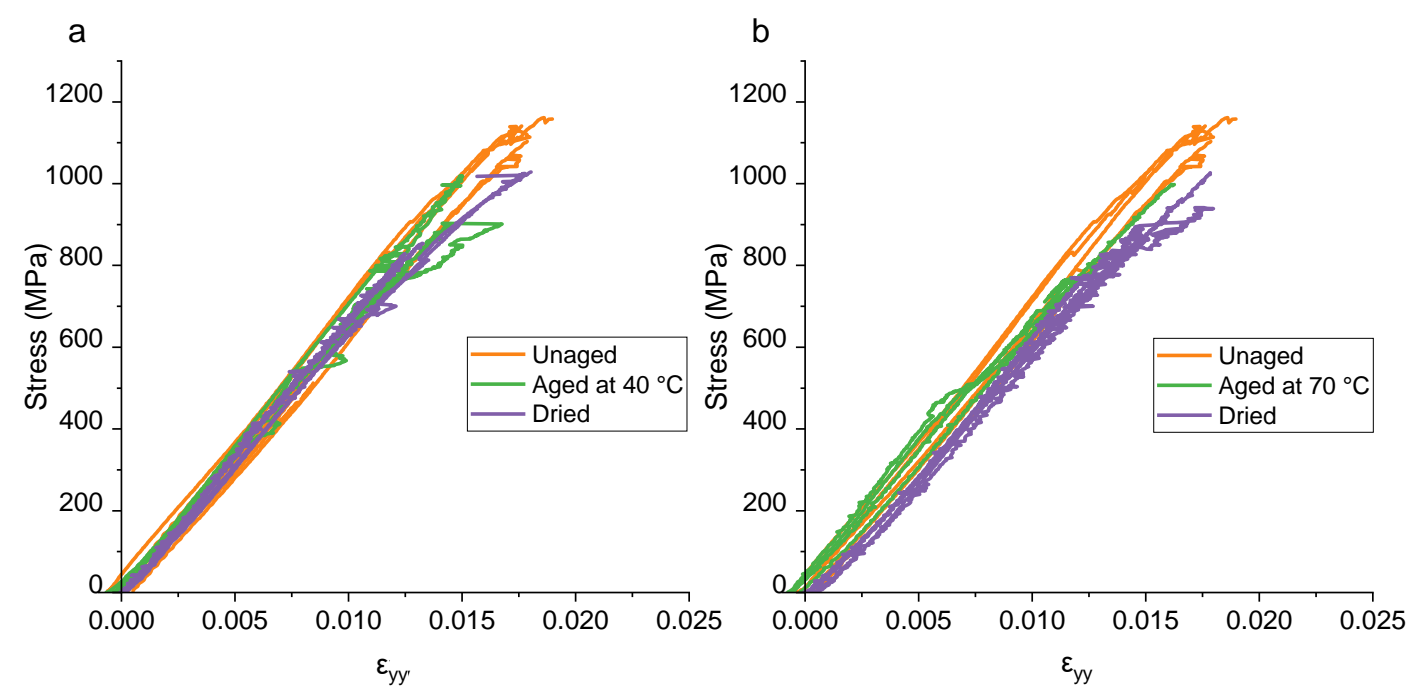

Figure 6: Stress-strain curves of tensile test on [0/90] samples at unaged, aged at $40{ }^{\circ} \mathrm{C}$ (a) and 70 ${ }^{\circ} \mathrm{C}(b)$ and dried after aging states
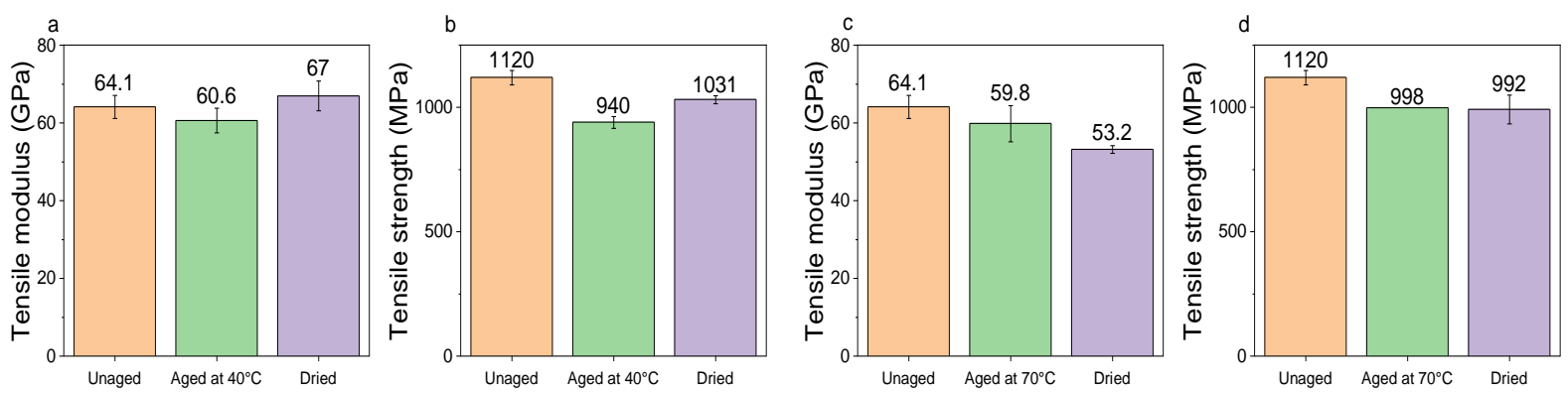

Figure 7: The evolution of tensile modulus $(a, c)$ and tensile strength $(b, d)$ from longitudinal tensile test performed on samples at reference (unaged), aged at both $40{ }^{\circ} \mathrm{C}$ and $70^{\circ} \mathrm{C}$ and dried after aging.

\subsubsection{Off-axis tensile tests}


Tensile tests on samples with $[+45 /-45]_{4}$ reinforcement lay-up were conducted in the same condition as longitudinal tensile test and related stress-strain curves are depicted in Figure 8. In all studied cases, the recorded longitudinal $\left(\varepsilon_{\mathrm{yy}}\right)$ and transverse $\left(\varepsilon_{\mathrm{xx}}\right)$ strains are perfectly symmetrical. For samples aged at $40{ }^{\circ} \mathrm{C}$, a clear decrease of stress and strain levels at failure was partially recovered after drying. Regarding samples aged $70{ }^{\circ} \mathrm{C}$, the maximum strain level was markedly reduced in parallel with a slight increase in yield stress. After drying, the yield stress continued to increase to nearly reach shear ultimate stress. In addition, one can see that the aged and dried maximum strain at breaking are similar in each studied case, suggesting a non-reversible damage of material properties even at low aging temperature and after drying. In order to further explore the influence of aging temperature on off-axis behaviour, the in-plane shear modulus $G$ is calculated from longitudinal test results for each sample in unaged, aged and dried states as follow:

$$
\frac{1}{G}=\frac{4}{E_{45}}-\frac{1}{E_{L}}-\frac{1}{E_{T}}+2 \frac{v_{L T}}{E_{L}}
$$

Equation 12

where $E_{L}, E_{T}$ and $v_{L T}$ are tensile moduli and Poisson's ratio obtained from tensile tests in longitudinal and transverse directions, $E_{45}$ is the apparent modulus measured from off-axis test. In this study $E_{L}=$ $E_{T}$ since the biaxial reinforcement used is balanced. From Figure 9.a and Figure 9.c, one can see the trend of the evolution of the shear modulus during study steps. A similar trend is found when samples are aged at $40{ }^{\circ} \mathrm{C}$ or $70{ }^{\circ} \mathrm{C}$ with a drop in shear modulus by the effect of aging. It is clear that the presence of water in the microstructure and more specifically at fibre / matrix interface enhances the hydrolysis reaction, which leads to a drop in shear modulus. This drop is more significant at lower aging temperature $\left(40{ }^{\circ} \mathrm{C}\right)$ suggesting that higher aging temperature can lead to a post-curing effects. The effect of water on shear modulus of studied composites is found to be irreversible, since no recovery is found after drying. The permanent degradation of samples aged at $40{ }^{\circ} \mathrm{C}$ and then dried is found to be different from longitudinal test results presented here above, where a full recovery is observed denying the hypothesis that only plasticization occurs when the material is aged at $40{ }^{\circ} \mathrm{C}$. Furthermore, shear strength results are presented in Figure 9.b and Figure 9.d. The ultimate stress at breakage recorded on aged samples at $40{ }^{\circ} \mathrm{C}$ and $70{ }^{\circ} \mathrm{C}$ shows a similar trend with a significant drop, which is more important for samples aged at $40{ }^{\circ} \mathrm{C}(25 \%)$ compared to samples aged at $70{ }^{\circ} \mathrm{C}(17 \%)$. After elimination of water absorbed during aging at both temperatures by means of desiccation, a partial recovery of shear strength is recorded. The permanent loss of around $10 \%$ in shear strength is caused by irreversible chemical effects of interactions between water and polymer molecules.

From a molecular point of view in the presence of water, there is an important amount of intermolecular hydrogen bonding between polymer chains essentially due to the preferred hydrogen bonding at polar sites which makes the formation of water clusters possible for certain systems ${ }^{38}$. When water molecules accumulate at the level of free volumes already present in the polymer between its macromolecular chains, they begin to disrupt the intermolecular bonding, which leads to a temporary lowering of the material physical and mechanical properties such as its rigidity. When a load is applied, the material 
response is different with a generally increased deformation. In such a case, water favour the formation of microcracks at the surface or in the bulk matrix and could cause weakening of the fibre/matrix interfacial adhesion. For fibre-dependent properties in the case of axial tensile test, the breakage of intermolecular bonds interactions, induced by plasticization in polymer matrix composites immersed in water, generally induce a lowering of material modulus and strength, but may lead to higher levels of elongation at break and better impact resistance; i.e. plasticization could favour composite softening providing greater plastic deformation, which promotes a ductile fracture of the composite. On the other hand, physical and chemical degradation caused by water presence can alter significantly the dependent properties of the polymer matrix, such as shear, compression and interlaminar properties. When water is eliminated from the structure, polymer mobility is often found to decrease. Subsequently, materials properties may be totally recovered in case of no chemical degradation have occurred during the immersion time.
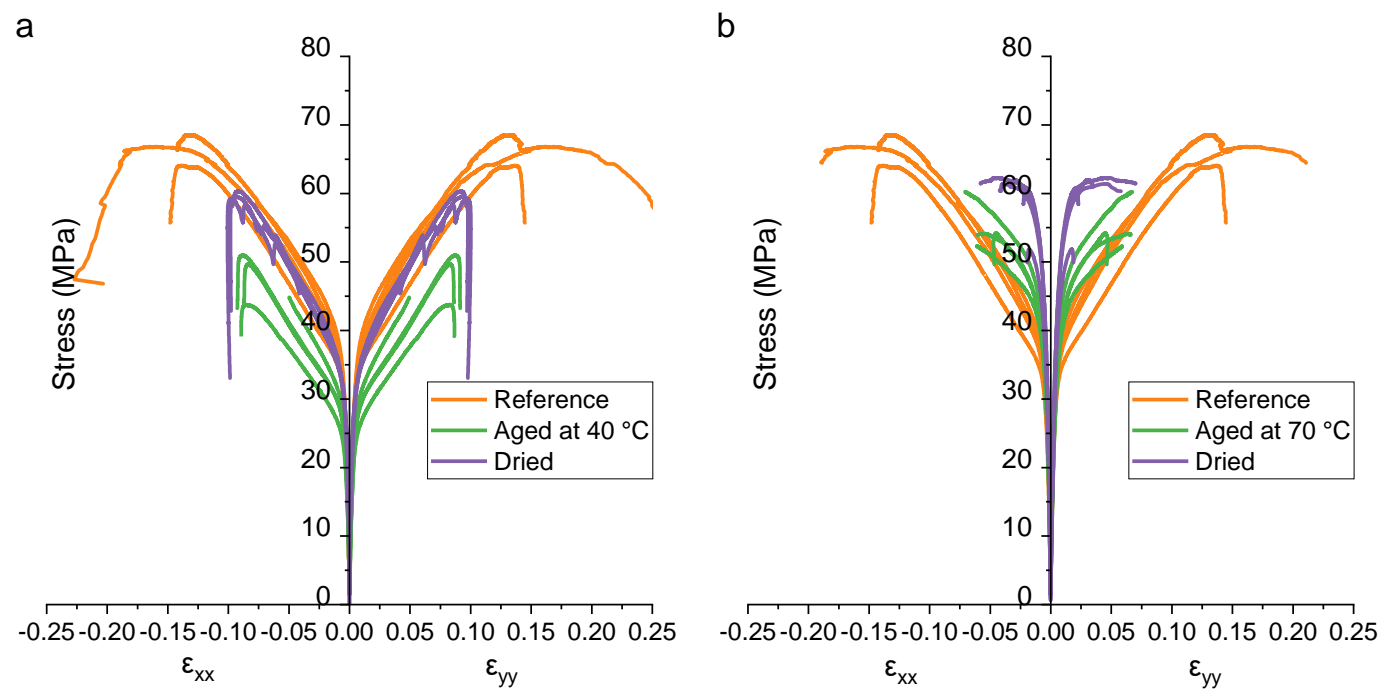

Figure 8: Stress-strain curves of tensile test on [+45/-45] samples at unaged, aged at $40{ }^{\circ} \mathrm{C}(\mathrm{a})$ and $70{ }^{\circ} \mathrm{C}(b)$ and dried after aging states
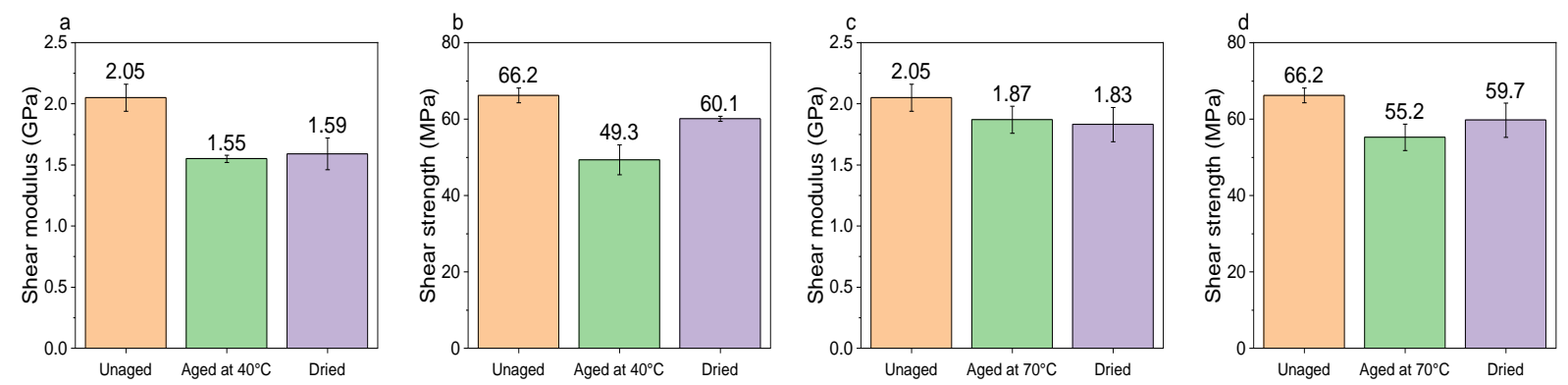

Figure 9: Off-axis tensile test results represented by shear modulus ( $a$ and $c$ ) and shear strength ( $b$ and d) performed on samples at reference (unaged), aged at both $40{ }^{\circ} \mathrm{C}$ and $70{ }^{\circ} \mathrm{C}$ and dried after aging

\subsubsection{Modal analysis}


In order to better understand the effect of immersion time and so moisture content on the material mechanical properties, non-destructive modal analysis was conducted during the immersion and the resonance frequency of the first tension-compression mode was recorded. By measuring the laminate density and the impulsive frequency response, the dynamic elastic modulus is calculated by means of Equation 2. The evolution of the dynamic elastic modulus of CF / Elium composite samples during aging at $40{ }^{\circ} \mathrm{C}$ and $70{ }^{\circ} \mathrm{C}$ and during drying are presented in Figure 10. Each point represents an average of measurements performed on at least 5 samples.

In the case of samples aged at $40{ }^{\circ} \mathrm{C}$ (Figure 10.a and Figure 10.b), a slight and gradual decrease in dynamic elastic modulus is noticed while samples are immersed. Once saturation is reached and samples are dried, a recovery of the calculated dynamic elastic modulus is found. For off-axis samples, a similar trend is found and presented in Figure 10.b. A decrease of the elastic modulus during immersion is followed by a recovery while drying. Similarities are found in the case of coupons aged at $70{ }^{\circ} \mathrm{C}$ (Figure 10.c and Figure 10.d) compared to those aged at $40^{\circ} \mathrm{C}$, but, when compared to quasi-static tensile test results, dynamic modulus drop seems to be totally recoverable after drying step even at high aging temperature, while clear irreversible degradation took place when tensile tests are performed as presented in Figure 7 and Figure 9. It is clear that vibratory analysis, which is considered as highfrequency resonance method, give precious information about material behaviour when subjected to accelerated aging. The evolution of the global or local reduction in rigidity of the studied laminates can be considered as indicators of local damage. Globally, the increase of water content in the composite leads to a decrease of its mechanical properties. In a similar way, desorption of water during drying stage gives rise to an increase of the material properties. Compared to quasi-static tests, the low deformation level of vibratory analysis does not allow to perceive the permanent degradation after aging at $70{ }^{\circ} \mathrm{C}$. 

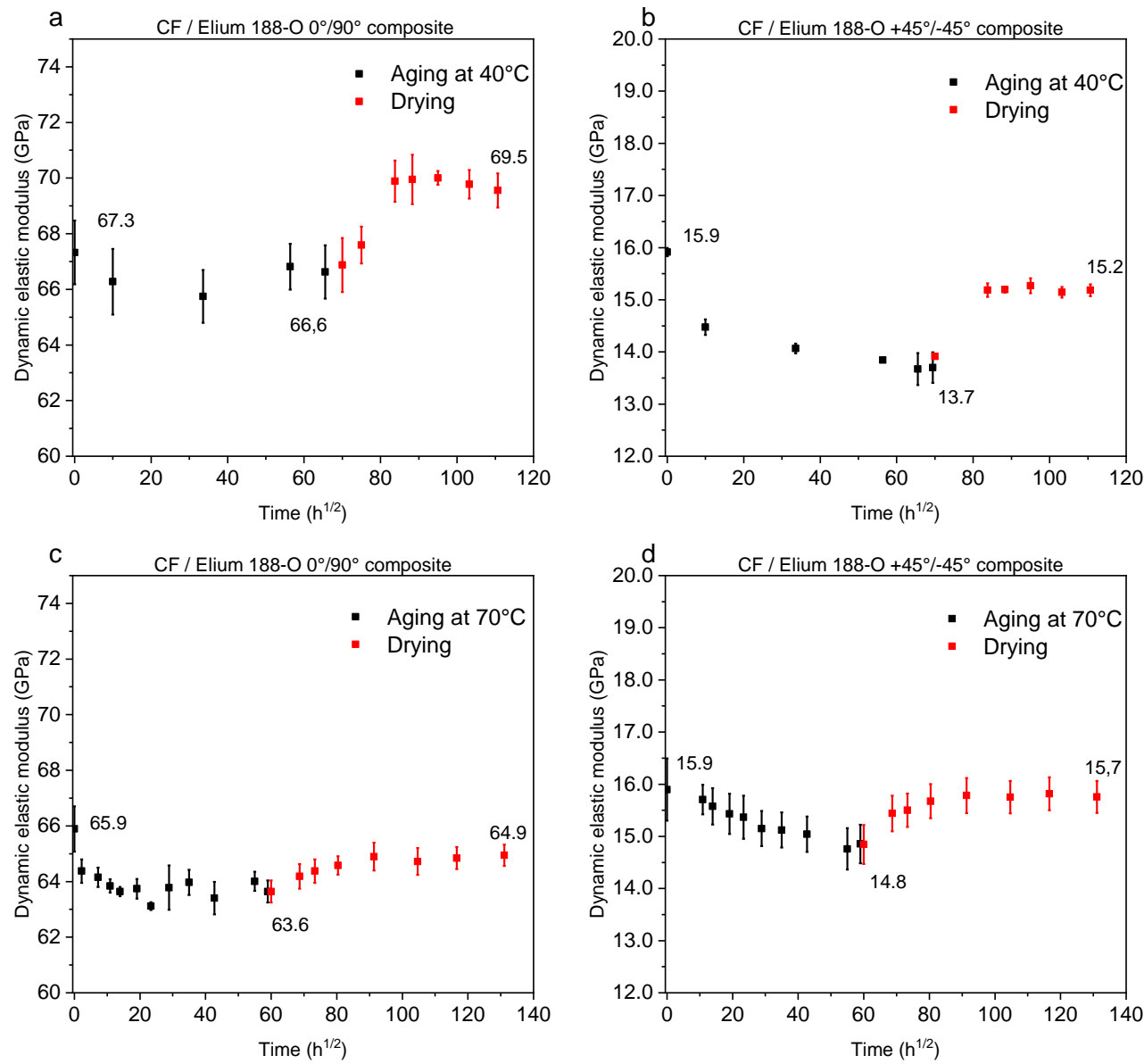

Figure 10: Modal analysis results represented by dynamic elastic modulus performed on [0/90] 4 and [+45/-45] samples at reference (unaged), aged at $40{ }^{\circ} \mathrm{C}(a, b)$ and $70{ }^{\circ} \mathrm{C}(c, d)$ and dried after aging

\subsubsection{Dynamic mechanical analysis}

The literature review highlights that hydrothermal aging and more specifically water uptake could promote physical and chemical degradations, which can affect mechanical properties of polymers. In order to evaluate the effect of the hydrothermal aging protocol at two distinct temperatures, DMA tests were performed on neat Elium resin, CF / Elium composites ([0/90] $]_{4}$ and [+45/-45 $\left.]_{4}\right)$ samples at reference, final aged and dried final states. The related results are presented in Figure 11 and Figure 12. Neat resin samples

In Figure 11.a, the loss factor $(\tan \delta)$ - temperature spectrum of neat resin sample before aging present a well-defined peak attributable to resin relaxation. The corresponding temperature of the peak is considered as the material glass transition temperature $\mathrm{T}_{\mathrm{g}}$. After aging at $40{ }^{\circ} \mathrm{C}$, a slight shifting of loss factor curve is observed. It is considered that this reduction of $\tan \delta$ peak temperature and area under curve at $40{ }^{\circ} \mathrm{C}$ immersion is related to plasticization characterized by an increased chain mobility, which is considered as a hydrothermal physical aging ${ }^{48}$. When immersed at $70{ }^{\circ} \mathrm{C}$, a significant change of curve shape marked by the apparition of two distinct peaks is reported in Figure 12.a. When coupons are dried, $(\tan \delta)$ - temperature spectrum retrieve their initial shape, i.e. a well-defined peak but at 
relatively higher temperatures, which is in average $10{ }^{\circ} \mathrm{C}$ higher than temperature found at initial dry state. The newly formed second peak of $\tan \delta$ curve related to resin samples aged at $70{ }^{\circ} \mathrm{C}$ coincides with the peak of the dried material after aging. As mentioned above, as neat resin specimens present high water content level after large immersion duration, the temperature sweep from $50{ }^{\circ} \mathrm{C}$ to $160{ }^{\circ} \mathrm{C}$ during test promotes desorption of water from tested samples and thus the appearance of a "second glass transition" corresponding to the dry state. A similar behaviour was reported by $\mathrm{Xu}$ and Dillard ${ }^{49}$ on three different epoxy based conductive adhesives. In addition, Alessi et al. draw a connection between extended aging duration and temperatures, which are responsible of the formation of a less uniform network compared to unaged polymer, and the formation of $\tan \delta$ distinct relaxation peaks, indicating a severe heterogeneity induced by water uptake. In fact, the coupled effects of water and temperatures may cause synergic results such as plasticization, molecular degradation, post-curing reactions and the formation of pseudo-cross-links by multiple hydrogen bonds with water ${ }^{4}$. In a recent study, it was found that the increase of moisture uptake level over time of carbon fibre reinforced Elium 150 composites lead to an increase in the $\tan \delta$ curve due to the heterogeneity of the structure ${ }^{39}$. In fact, the increase of free volume between monomer units caused by water molecules ingress affects the local polymerization reaction and molecular mobility. Regarding the formulation of Elium resin, which is made from bloc copolymers, the presence of water can promote phase separation and thus giving rise to a peak-splitting in $\tan \delta$ curve and the apparition of a new $\mathrm{T}_{\mathrm{g}}$.

One can also see the shifting of the "first peak" towards lower temperatures, which is expected due to the increase of chain mobility after water uptake. After drying, the increase of $T_{g}$ of neat Elium samples is related to irreversible chemical modifications of the main macromolecular chain such as further polymerisation reactions in already water plasticized material. This phenomenon is all the more important as the ageing temperature is higher as it can be seen by comparing $\tan \delta$ curve amplitude of dried samples.

Regarding the storage modulus evolution of studied Elium 188-O neat resin (Figure 11.b and Figure 12.b), for initial non aged specimens, the average storage modulus was about $2.12 \mathrm{GPa}$. When exposed to hydrothermal aging, the storage modulus decreased by about $18 \%$ and $33 \%$ after aging at $40{ }^{\circ} \mathrm{C}$ and $70{ }^{\circ} \mathrm{C}$, respectively. After water desorption, dried samples which were aged at $40{ }^{\circ} \mathrm{C}$ exhibits a full recovery of their storage modulus, whilst samples aged at $70{ }^{\circ} \mathrm{C}$ and then dried presented a slight permanent loss of their storage modulus by around $8 \%$. It is then clear that water effects on Elium 188$\mathrm{O}$ resin are different for both studied temperatures.

To conclude, it appears that water absorption and polymerisation of polymers have opposite effects on $\mathrm{T}_{\mathrm{g}}$ (referred to the loss factor peak); the former tends to lower the transition temperature and the latter enhancing it.

\section{Composite samples}

By analysing DMA results of composites samples for both [0/90] $]_{4}$ and [+45/-45] specimens given respectively by Figure 11.c to Figure 11.f and Figure 12.c to Figure 12.f, an overall similar behaviour 
as found for neat resin samples can be observed due in particular to the stability of carbon fibre over aging conditions and temperature range. It is worth noting that the presence of carbon fibres in the composite markedly reduce tan $\delta$ peak level compared to neat resin results ( $~ 0.4$ compared to 1.06$)$ due to their constraints during the matrix relaxation ${ }^{4}$. Composite samples aged at $40{ }^{\circ} \mathrm{C}$ exhibited a slight lowering of $\tan \delta$ peak temperature ( $\mathrm{T}_{\mathrm{g}}$ ) so a shifting to left side due to plasticization of the matrix caused by enhanced chain mobility and shorter end group due to chain scission in the presence of water as presented in Figure 11.c and Figure 11.e. It is also noted the appearance of a "shoulder" in the temperature range of $70-100{ }^{\circ} \mathrm{C}$ on aged curves due to the presence of water, whereas unaged and dried samples show smooth curves with no shoulder detected during temperature scanning. After drying step, a significant shifting of $\tan \delta$ curve towards higher temperatures is noted. For all dried samples, the $\mathrm{T}_{\mathrm{g}}$ is around $132{ }^{\circ} \mathrm{C}$ which is high compared to measured unaged $\mathrm{T}_{\mathrm{g}}$, which range between $103{ }^{\circ} \mathrm{C}$ to 111 ${ }^{\circ} \mathrm{C}$. The same explanation as adopted for neat resin may be applied here, since the polymer matrix in the composite could exhibit further polymerisation reaction resulting in an increase in chain length and molecular weight after prolonged exposure to relatively high temperatures humid environments. With respect to samples aged at $70{ }^{\circ} \mathrm{C}$, results presented in Figure 12.c and Figure 12.e showed peak-splitting, the first peak corresponding to the $\mathrm{T}_{\mathrm{g}}$ of unaged samples and the second to the dried samples. The same behaviour is reported previously in this section for neat resin coupons aged at $70{ }^{\circ} \mathrm{C}$ and was related to high moisture content and aging temperature, favouring further polymerisation reactions, and to the synergic effect of temperature gradient during DMA test, which induces desorption and the raise of a dried state.

It is also interesting to compare $\tan \delta$ curve amplitude of dried samples after aging at $40{ }^{\circ} \mathrm{C}$ (Figure 11.c and Figure 11.e ) and $70{ }^{\circ} \mathrm{C}$ (Figure 12.c and Figure 12.e). Tan $\delta$ curve amplitude for samples dried after immersion at $40{ }^{\circ} \mathrm{C}$ is 0.49 in average, whereas for samples immersed at $70{ }^{\circ} \mathrm{C}$ and then dried, the amplitude is about 0.72 , compared to 0.41 at unaged state. This higher loss factor level after drying reveals the non-reversibility of aging mechanisms after immersion at both $40{ }^{\circ} \mathrm{C} 70{ }^{\circ} \mathrm{C}$ compared to unaged state. In fact, the higher loss factor, the higher damping of the material, since the loss factor is mathematically defined as the ratio of loss modulus and storage modulus, and so higher molecular mobility which affects the material stiffness. In addition, high damping ratio is usually related to inefficient fibre/matrix bonding ${ }^{50}$.

Finally, storage modulus of composite samples from $[0 / 90]_{4}$ and $[+45 /-45]_{4}$ laminates before aging at $40{ }^{\circ} \mathrm{C}$, presented in Figure 11.d and Figure 11.f, were $22.7 \mathrm{GPa}$ and 7.43 GPa, respectively. After reaching saturation of water content, DMA tests revealed a drop of storage modulus by around $17 \%$ and $12 \%$, respectively. Then after desorption, a partial recovery was found for $[0 / 90]_{4}$ samples, whilst a full recovery is reported for [+45/-45] $]_{4}$ configurations. In the case of immersion at $70{ }^{\circ} \mathrm{C}$, storage modulus presented by Figure 12.d and Figure 12.f exhibit similar evolution. Indeed, the initial drop of storage modulus at aged state of around $10 \%$ for both composite configurations is lower than the loss reported when samples were aged at $40{ }^{\circ} \mathrm{C}$, which can be related to further polymerisation induced by higher 
temperature. When water is desorbed, a partial recovery is outlined for $[0 / 90]_{4}$ samples. On the other hand, a near full recovery of storage modulus is reported for $[+45 /-45]_{4}$ samples. This leads to confirm that, when samples are aged at higher temperature, coupled phenomena could take place in the material. Polymer matrix have tendency to plasticize due to water presence and may reach hydrolysis and further chemical irreversible degradation for prolonged exposure duration. In return, polymerisation reactions could take place in the presence of initially incomplete reactions.
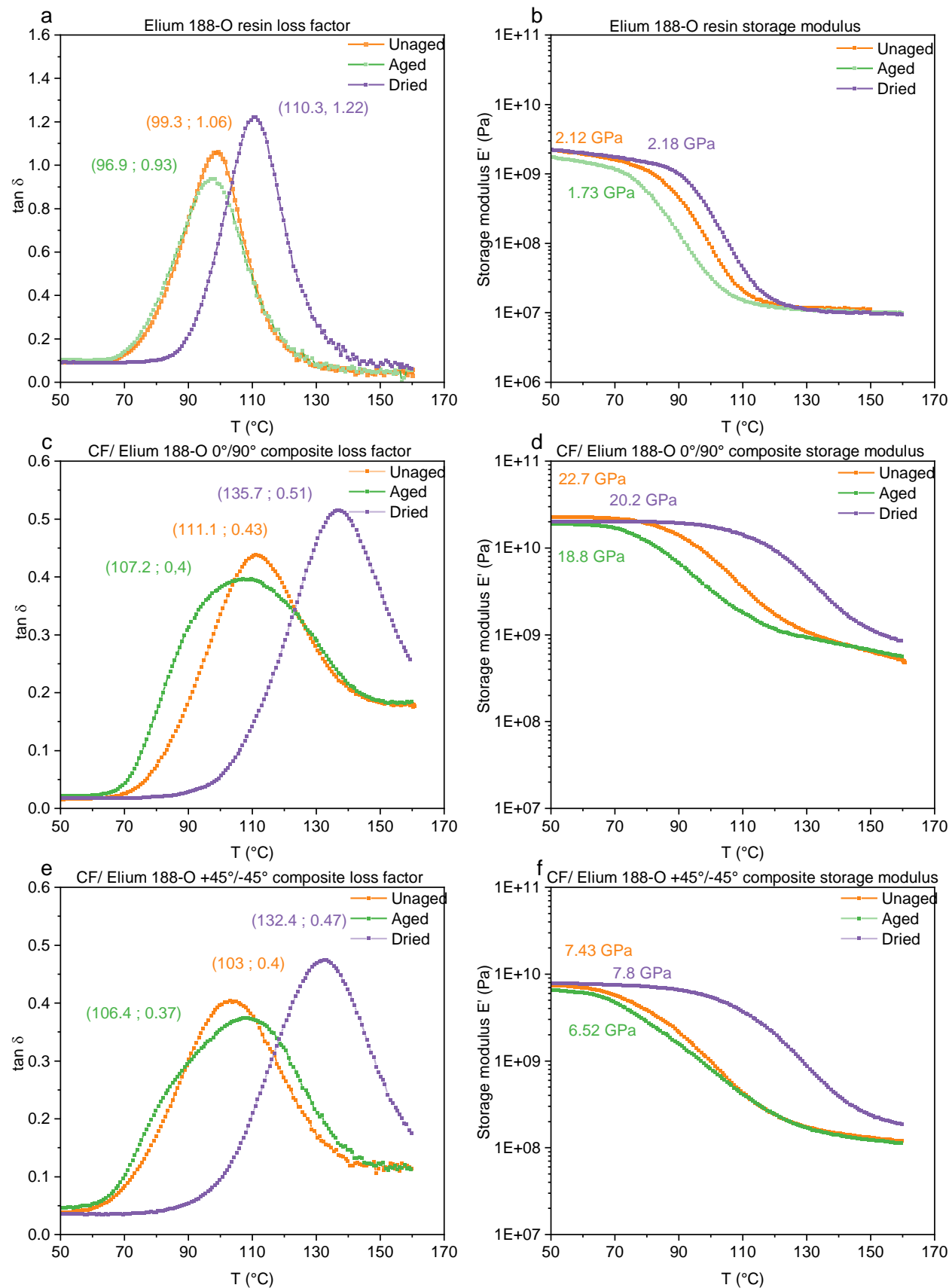

Figure 11 : DMA loss factor ( $a, c$ and $e$ ) and storage modulus ( $b, d$ and $f$ ) results of unaged, aged at $40{ }^{\circ} \mathrm{C}$ and dried samples of neat Elium resin and CF/Elium composites 

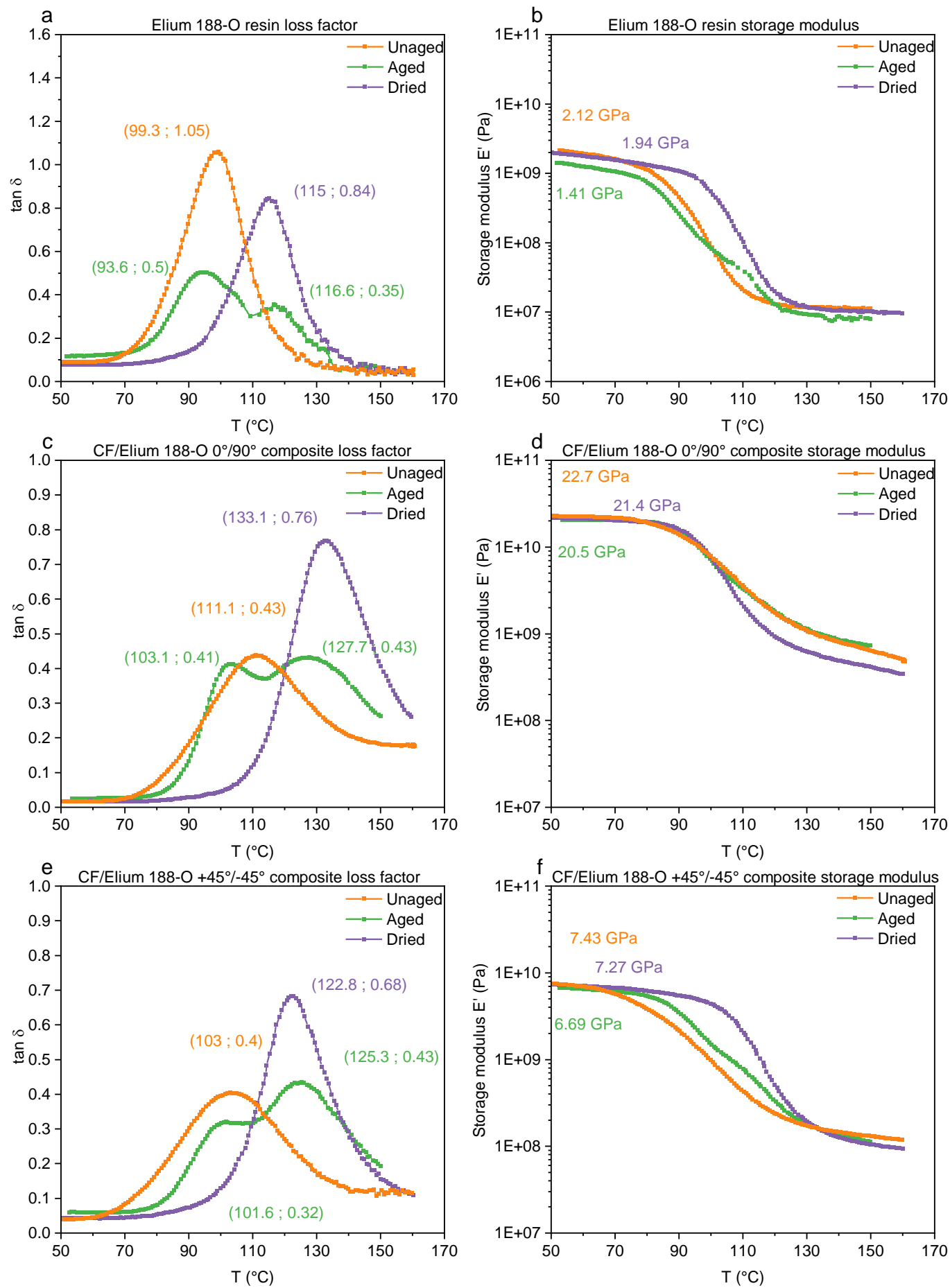

Figure 12 : DMA loss factor ( $a, c$ and $e$ ) and storage modulus ( $b, d$ and $f$ ) results of unaged, aged at 70 ${ }^{\circ} \mathrm{C}$ and dried samples of neat Elium resin and $\mathrm{CF} /$ Elium composites

\section{Conclusion}

In the present work, original results from accelerated aging and durability tests are presented for a novel acrylic thermoplastic matrix and composites. The absorption and desorption behaviours were monitored for neat thermoplastic Elium 188-O resin and carbon fibre reinforced Elium composite at $40{ }^{\circ} \mathrm{C}$ and 70 
${ }^{\circ} \mathrm{C}$. Mechanical quasi-static, dynamic and vibratory analyses were performed at unaged, saturated and dried states.

- Gravimetric measurements showed dissimilar absorption behaviour for neat resin samples aged at different temperatures. At $40{ }^{\circ} \mathrm{C}$, the resin showed a Fickian behaviour, while a fractional mass uptake profile is recorded for samples with various dimensions aged at higher temperatures. In case of composites, a similar non-Fickian behaviour is reported, with an initial increasing water uptake profile followed by a lower slope until reaching a saturation plateau.

- This behaviour agreed well with the Carter \& Kibler diffusion model. The comparison of identified numerical model parameters at both aging temperatures for neat resin and composite samples showed that, while neat resin diffusion coefficients increased with increasing temperature, composite diffusion coefficients decreased with increased aging temperature, in parallel to a significant increase in water content at saturation.

- Drying test at $40{ }^{\circ} \mathrm{C}$ was performed at the end of aging steps and water desorption behaviour was well described by Fick's law. Identified desorption coefficients of neat resin are independent from aging temperature as well as the excess in desorbed water content. However, desorption coefficients of composite samples decreased with increasing aging temperature. The permanent mass loss after drying can be related to an irreversible internal chemical degradation of the matrix or the fibre matrix interphase during prolonged exposure.

- Composite longitudinal tensile properties are found to be completely reversible at $40{ }^{\circ} \mathrm{C}$, but a significant permanent loss is reported when aging occurred at higher temperature. However, off-axis tensile properties presented more dependency and irreversibility in both aging conditions.

- Dynamic rigidity monitored by non-destructive modal analysis during both aging and drying steps showed that water ingress induces a drop in the composite dynamic elastic modulus, which was totally reversible at both moderate and high temperatures.

- Dynamic mechanical analysis results showed notable differences between aging conditions for both neat resin and composite samples. At saturation, glass transition temperatures were slightly lowered in particular at $70{ }^{\circ} \mathrm{C}$, where a splitting in the curve giving rise to a double peak was observed. After drying, a considerable rise of transition temperature is recorded for all studied materials. Storage modulus evolution was similar to static tensile modulus. An initial considerable drop is partially recovered after drying.

In light of these results, the material has good durability after accelerated aging at $40{ }^{\circ} \mathrm{C}$ as properties were partially recovered. However, the aging at higher temperature induced a non-reversible degradation. Further studies may concern the coupling effects of mechanical load and aging by mean of in-situ tests in order to get closer to real operating conditions. 


\section{Acknowledgement}

Authors would like to acknowledge Occitanie region and REV Inside, France for the support of this project. The authors would also like to thank Dr Pierre GERARD from ARKEMA for the supply of Elium $^{\mathrm{TM}}$ resin.

\section{Declaration of Conflicting Interests}

The author(s) declared no potential conflicts of interest with respect to the research, authorship, and/or publication of this article.

\section{Funding}

The author(s) received no financial support for the research, authorship, and/or publication of this article.

\section{References:}

1. ICOMIA. Recreational Boating Industry Statistics 2017, www.icomia.org (2018).

2. Arhant M, Davies P. Thermoplastic matrix composites for marine applications. In: Pemberton R, Summerscales J, Graham-Jones J (eds) Marine Composites: Design and Performance. Elsevier, 2019, pp. 31-53.

3. Marouani S, Curtil L, Hamelin P. Ageing of carbon/epoxy and carbon/vinylester composites used in the reinforcement and/or the repair of civil engineering structures. Compos Part B Eng 2012; 43: 2020-2030.

4. Alessi S, Pitarresi G, Spadaro G. Effect of hydrothermal ageing on the thermal and delamination fracture behaviour of CFRP composites. Compos Part B Eng 2014; 67: 145-153.

5. Uthaman A, Xian G, Thomas S, et al. Durability of an epoxy resin and its carbon fiber-reinforced polymer composite upon immersion in water, acidic, and alkaline solutions. Polymers (Basel); 12. Epub ahead of print 2020. DOI: 10.3390/polym12030614.

6. Shen C-H, Springer GS. Moisture Absorption and Desorption of Composite Materials. J Compos Mater 1976; 10: 2-20.

7. Weitsman YJ. Fluid Effects in Polymers and Polymeric Composites. Boston, MA: Springer US. Epub ahead of print 2012. DOI: 10.1007/978-1-4614-1059-1.

8. Summerscales J. Durability of Composites in the Marine Environment. In: Davies P, Rajapakse YDS (eds) Durability of Composites in a Marine Environment. Solid Mechanics and Its Applications. Dordrecht: Springer Netherlands,2014, pp. 1-13.

9. Summerscales J. Materials selection for marine composites. In: Pemberton R, Summerscales J, Graham-Jones J (eds) Marine Composites: Design and Performance. Elsevier, 2019, pp. 3-30. 
10. Ameli A, Datla N V., Papini M, et al. Hygrothermal properties of highly toughened epoxy adhesives. J Adhes 2010; 86: 698-725.

11. Bao L-R, Yee AF, Lee CYC. Moisture absorption and hygrothermal aging in a bismaleimide resin. Polymer (Guildf) 2001; 42: 7327-7333.

12. Carter HG, Kibler KG. Langmuir-Type Model for Anomalous Moisture Diffusion In Composite Resins. J Compos Mater 1978; 12: 118-131.

13. Gurtin ME, Yatomi C. On a Model for Two Phase Diffusion in Composite Materials. J Compos Mater 1979; 13: 126-130.

14. Colin X. Nonempirical Kinetic Modeling of Non-fickian Water Absorption Induced by a Chemical Reaction in Epoxy-Amine Networks. In: Davies P, Rajapakse YDS (eds) Durability of Composites in a Marine Environment 2. Cham: Springer, 2018, pp. 1-18.

15. Fichera M, Carlsson LA. Moisture transport in unidirectional carbon/vinylester panels with imperfect fiber/matrix interface. J Compos Mater 2016; 50: 751-760.

16. Galpayage Dona KNU, Du E, Carlsson LA, et al. Modeling of water wicking along fiber/matrix interface voids in unidirectional carbon/vinyl ester composites. Microfluid Nanofluidics 2020; 24: 31 .

17. De Souza Rios A, De Amorim WF, De Moura EP, et al. Effects of accelerated aging on mechanical, thermal and morphological behavior of polyurethane/epoxy/fiberglass composites. Polym Test 2016; 50: 152-163.

18. Guermazi N, Ben Tarjem A, Ksouri I, et al. On the durability of FRP composites for aircraft structures in hygrothermal conditioning. Compos Part B Eng 2013; 85: 294-304.

19. Davies P, Le Gac P-Y, Le Gall M. Influence of Sea Water Aging on the Mechanical Behaviour of Acrylic Matrix Composites. Appl Compos Mater 2017; 24: 97-111.

20. Davies P, Arhant M. Fatigue Behaviour of Acrylic Matrix Composites: Influence of Seawater. Appl Compos Mater 2019; 26: 507-518.

21. Nash NH, Portela A, Bachour-Sirerol CI, et al. Effect of environmental conditioning on the properties of thermosetting- and thermoplastic-matrix composite materials by resin infusion for marine applications. Compos Part B Eng 2019; 177: 107271.

22. Nash N, Sirerol CB, Manolakis I, et al. Thermoplastic infusible resin systems: Candidates for the marine sector? In: ECCM 2018 - 18th European Conference on Composite Materials. Athens, 2020.

23. Chilali A, Zouari W, Assarar M, et al. Effect of water ageing on the load-unload cyclic behaviour of flax fibre-reinforced thermoplastic and thermosetting composites. Compos Struct 2017; 183: 309-319.

24. Kazemi ME, Shanmugam L, Lu D, et al. Mechanical properties and failure modes of hybrid fiber reinforced polymer composites with a novel liquid thermoplastic resin, Elium ${ }^{\circledR}$. Compos Part A Appl Sci Manuf 2019; 125: 105523. 
25. Arkema. Elium 188: Technical datasheet. 2015.

26. Cadu T, Berges M, Sicot O, et al. What are the key parameters to produce a high-grade bio-based composite? Application to flax/epoxy UD laminates produced by thermocompression. Compos Part B Eng 2018; 150: 36-46.

27. Springer GS, Loos AC. Moisture Absorption of Graphite-Epoxy Composites Immersed in Liquids and in Humid Air. J Compos Mater 1979; 13: 131-147.

28. Deroiné M, Le Duigou A, Corre Y, et al. Accelerated ageing of polylactide in aqueous environments: Comparative study between distilled water and seawater. Polym Degrad Stab 2014; 108: 319-329.

29. Popineau S, Rondeau-Mouro C, Sulpice-Gaillet C, et al. Free/bound water absorption in an epoxy adhesive. Polymer (Guildf) 2005; 46: 10733-10740.

30. Krauklis AE, Gagani AI, Echtermeyer AT. Near-infrared spectroscopic method for monitoring water content in epoxy resins and fiber-reinforced composites. Materials (Basel); 11. Epub ahead of print 2018. DOI: 10.3390/ma11040586.

31. Philippe LVS, Lyon SB, Sammon C, et al. Validation of electrochemical impedance measurements for water sorption into epoxy coatings using gravimetry and infra-red spectroscopy. Corros Sci 2008; 50: 887-896.

32. Musto P, Ragosta G, Mascia L. Vibrational Spectroscopy Evidence for the Dual Nature of Water Sorbed into Epoxy Resins. Epub ahead of print 2000. DOI: 10.1021/cm9906809.

33. Jelinski LW, Dumais JJ, Cholli AL, et al. Nature of the water-epoxy interaction. Macromolecules 1985; 18: 1091-1095.

34. Wang W, Jin Y, Su Z. Spectroscopic study on water diffusion in poly(ester urethane) block copolymer matrix. J Phys Chem B 2009; 113: 15742-15746.

35. Chin JW, Nguyen T, Aouadi K. Sorption and Diffusion of Water, Salt Water, and Concrete. $J$ Appl Polym Sci 1998; 71: 483-492.

36. Christmann A, Ienny P, Quantin JC, et al. Mechanical behaviour at large strain of polycarbonate nanocomposites during uniaxial tensile test. Polymer (Guildf) 2011; 52: 4033-4044.

37. Corn S, Dupuy JS, Ienny P, et al. Vibration analysis techniques for detecting filler-matrix decohesion in composites. Rev des Compos des matériaux avancés 2012; 22: 77-90.

38. Moghbelli E, Banyay R, Sue HJ. Effect of moisture exposure on scratch resistance of PMMA. Tribol Int 2014; 69: 46-51.

39. Barbosa LCM, Santos M, Oliveira TLL, et al. Effects of moisture absorption on mechanical and viscoelastic properties in liquid thermoplastic resin/carbon fiber composites. Polym Eng Sci 2019; 59: 2185-2194.

40. Thomason JL. The interface region in glass fibre-reinforced epoxy resin composites: 2. Water absorption, voids and the interface. Composites 1995; 26: 477-485.

41. Hendlmeier A, Marinovic LI, Al-Assafi S, et al. Sizing effects on the interfacial shear strength 
of a carbon fibre reinforced two-component thermoplastic polymer. Compos Part A Appl Sci Manuf 2019; 127: 105622.

42. Chateauminois A, Vincent L, Chabert B, et al. Study of the interfacial degradation of a glassepoxy composite during hygrothermal ageing using water diffusion measurements and dynamic mechanical thermal analysis. Polymer (Guildf) 1994; 35: 4766-4774.

43. Bao LR, Yee AF. Moisture diffusion and hygrothermal aging in bismaleimide matrix carbon fiber composites: Part II-woven and hybrid composites. Compos Sci Technol 2002; 62: 21112119.

44. Roy S, Xu WX, Park SJ, et al. Anomalous Moisture Diffusion in Viscoelastic Polymers: Modeling and Testing. J Appl Mech 2000; 67: 391.

45. Chen X, Zhao S, Zhai L. Moisture Absorption and Diffusion Characterization of Molding Compound. J Electron Packag 2005; 127: 460.

46. Feng J, Berger KR, Douglas EP. Water vapor transport in liquid crystalline and non-liquid crystalline epoxies. J Mater Sci 2004; 39: 3413-3423.

47. Nakamura K, Hatakeyama T, Hatakeyama H. Studies on bound water of cellulose by differential scanning calorimetry. 1981; 607-613.

48. Gao Y, Li C, Wang J, et al. Investigation on fatigue behavior and damage mechanism of C/BMI composites under hygrothermal environment. Polym Degrad Stab 2019; 169: 108989.

49. Xu S, Dillard DA. Environmental aging effects on thermal and mechanical properties of electrically conductive adhesives. J Adhes 2003; 79: 699-723.

50. Perret P, Chabert B, Gérard J-F. Viscoelastic study of carbon/epoxy unidirectional composite materials. Makromol Chemie Macromol Symp 1989; 23: 139-147. 